\title{
Textile Wastewater Treatment in a Spinning Disc Reactor: Improved Performances-Experimental, Modeling and SVM Optimization
}

\author{
Carmen Zaharia ${ }^{1}\left(\mathbb{D}\right.$, Florin Leon ${ }^{2} \mathbb{D}$, Silvia Curteanu ${ }^{3}$ and Eugenia Teodora Iacob-Tudose ${ }^{3, *}$ \\ 1 Department of Environmental Engineering and Management, "Cristofor Simionescu" Faculty of Chemical \\ Engineering and Environmental Protection, "Gheorghe Asachi" Technical University of Iasi, \\ 700050 Iasi, Romania; czah@ch.tuiasi.ro \\ 2 Department of Computer Science and Engineering, Faculty of Automatic Control and Computer Engineering, \\ "Gheorghe Asachi" Technical University of Iasi, 700050 Iasi, Romania; florin.leon@academic.tuiasi.ro \\ 3 Department of Chemical Engineering, "Cristofor Simionescu" Faculty of Chemical Engineering and \\ Environmental Protection, "Gheorghe Asachi” Technical University of Iasi, 700050 Iasi, Romania; \\ scurtean@ch.tuiasi.ro \\ * Correspondence: etudose@ch.tuiasi.ro; Tel.: +40-728447215
}

Citation: Zaharia, C.; Leon, F.; Curteanu, S.; Iacob-Tudose, E.T. Textile Wastewater Treatment in a Spinning Disc Reactor: Improved Performances-Experimental, Modeling and SVM Optimization. Processes 2021, 9, 2003. https:// doi.org/10.3390/pr9112003

Academic Editor: Davide Dionis

Received: 13 October 2021

Accepted: 6 November 2021

Published: 9 November 2021

Publisher's Note: MDPI stays neutral with regard to jurisdictional claims in published maps and institutional affiliations.

Copyright: (c) 2021 by the authors. Licensee MDPI, Basel, Switzerland. This article is an open access article distributed under the terms and conditions of the Creative Commons Attribution (CC BY) license (https:// creativecommons.org/licenses/by/ $4.0 /)$.

\begin{abstract}
The paper presents an experimental study regarding the treatment of a real textile wastewater using the spinning disc (SD) technology, either individually or associated with an advanced Fenton oxidation step. The SD efficiency was investigated by studying the color, suspended solids, or turbidity removals, at distinctive feeding flowrates (10-30 L/h) and disc rotating speeds (100-1500 rpm). The data revealed increasing removal trends and allowed to establish the highest removal values. Based on obtained experimental results, the wastewater treatment efficiency by SD technology was reasonably good and thus, the WW indicators can be improved within relatively short periods of time. Additionally, based on supervised learning algorithms, the study includes treatment modeling for turbidity and color removal, followed by turbidity removal optimization relying on the best learned models. Satisfactory results obtained with the modeling and optimization procedures provide useful predictions for the approached treatment processes. Furthermore, within this study, a Fenton oxidation process was applied to SD technology to minimize the color and solids content. The influence of $\mathrm{pH}$, hydrogen peroxide and ferrous ions concentrations was also investigated in order to establish the highest removal efficiencies. Overall, the SD technology applied in textile effluents treatment proved to be an appropriate and efficient alternative to classical mechanical step applied within the primary treatment step and, when associated with an advanced oxidative process in the secondary step, rendered good improvement, namely of $62.84 \%$ and $69.46 \%$ for color and respectively, suspended solids removal.
\end{abstract}

Keywords: discoloration; Fenton oxidation; SD technology; turbidity reduction; textile effluent treatment; SVM optimization

\section{Introduction}

One of the process intensification technologies often used in recent years for a diversity of applications is the spinning disc (SD) technology. Based on the centrifugal force action on a liquid film formed on a rotatable disc, the SD technology benefits of intense micromixing and thus, enhanced transport properties.

Due to a number of research studies on the spinning disc efficiency in different areas such as polymers production [1], nanoparticle manufacturing [2], biological treatments [3], a number of chemical process industries have adopted the SD technology with significant impacts on final product yield, quality, safety and costs [4]. Thus, new potential areas of spinning disc technology application are researched at this moment in order to take advantage of its many attributes $[5,6]$. In wastewater (WW) treatment system research, 
the spinning disc with a thin $\mathrm{ZnO}$ and $\mathrm{TiO}_{2}$ photocatalyst film was used to degrade some contaminants such as rhodamine B dye, methyl orange dye or 4-chlorobenzoic acid [7-9].

The WWs from the textile industry are considered to be a significant pollution source of persistent organic pollutants and also suspended/colloidal solids which might pose a risk to humans and the environment if are not well separated or eliminated by an efficient WW treatment technology [10-12]. Many unbonded dyes (more than $10 \%$ from the total dye amount occurring as residual dyes) are released into the WW after the dyeing process of different textile products (e.g., fabrics or wool, cloth, carpet, yarn or fiber finishing) and can be visually detected by specific WW color (due to dyes, auxiliary pigments, other colored additives) and also colloidal particles or suspended solids (e.g., disperse dyes, pigments, metal complex azo dyes, other agglomerates formed in the WW treatment process) $[11,13,14]$. Many dyes released in WWs and their breakdown products are toxic to life forms and that is why the discharge of dye-containing effluents into water environment is undesirable. The application of SD technology for a textile effluent treatment has certain advantages associated with the mono-block setup type requiring relatively limited space and which is commonly used for relatively small sized particles $(<1-5 \mathrm{~mm})$ presented in different aqueous systems in comparison with other types of equipment/installations used in the primary or secondary treatment step for solids removal (settlement tank/decanter, sand bead contact filter, de-greaser/flotation tank or mixing tank for coagulation-flocculation followed by a settlement tank etc.) and also, it allows for the effluent treatment efficiency improvement to an imposed level in the same mono-block setup by applying multiple combined treatment processes and operations, or recirculation of the treated effluent at the optimal operating conditions for certain requirements fulfilment.

This study was initiated in order to investigate, the SD technology efficiency on treatment of a textile effluent without association with any auxiliary mechanical-physical, chemical or biochemical process, mainly regarding the colloidal particles (turbidity) separation or treatment, after previously obtained experimental data on suspended solids and color removals proved to be successful [15]. Furthermore, the spinning disc technology applied to different industrial effluents can be improved using additional physical and/or chemical treatments such as advanced oxidative, reductive and/or adsorptive processes. The Fenton oxidation (FO) is one of the straightforward chemical treatments suitable to textile effluents highly loaded in organics (high loads can inhibit biological treatment) which is frequently used to reduce or minimize as much as possible the polluting organic loads in the secondary and/or tertiary (advanced) WW treatment steps, easily to operate and/or handle at relatively affordable costs (the supplementary concern of possible newly precipitates formation, i.e., ferrous and/or ferric hydroxides, can be safely solved with facilities for in-side reuse/recycling) [16,17]. This Advanced Oxidation Process (AOP) can destroy the dye molecules and decolorize the WW in very short time due to newly produced powerful oxidizing agents of hydroxyl radicals (HO-), thus reducing its organic pollution [16,18-21]. Moreover, hydroxyl radicals non-specifically oxidize organic compounds from the textile effluent at high reaction rates and remove the color and colorants such as dyes by AOP, resulting in aromatic cleavage of dye molecules [22,23]. The newly formed $\mathrm{Fe}^{3+}$ ions may catalyze hydrogen peroxide, causing it to be decomposed into water and oxygen, this mechanism being effective in case of a very high acidic $\mathrm{pH}(\mathrm{pH}<3.5)$, when hydrogen peroxide and $\mathrm{Fe}^{2+}$ ions are present in stabilized forms. At $\mathrm{pH}>4.0, \mathrm{Fe}^{2+}$ ions form easily $\mathrm{Fe}^{3+}$ ions which have a tendency to produce complex ferric hydroxide precipitates involving also coagulation easily achieved with bentonite as coagulation adjuvant $[16,21,24,25]$. Consequently, the FO efficiency applied as additional effluent chemical treatment mainly for color and suspended solids removal, was also investigated in the spinning disc reactor (SDR) setup. A subsequent modeling was applied to correlate the turbidity and the absorbance (as color indicator) with disc rotational speed, flowrate, working time and $\mathrm{pH}$. Afterwards, an optimization method was used to obtain maximum values 
for turbidity removal, based on the best learned models, including support vector machine, decision trees, random forests, and linear regression [26-30].

Higher than $90 \%$, or complete $(100 \%)$ removals of turbidity and color would be obtained if supplementary wastewater treatment steps will be applied after the Fenton oxidation, e.g., an advanced adsorption step (e.g., a filter with multi-beads of different adsorbents/filter materials such as sand, activated carbon or coal ashes, metallic oxides or mineral rocks), electro-flotation-coagulation, membrane processes or biological steps, but the main scope of our research is to demonstrate the improvement of textile effluent color and solids (turbidity) contents when the SDR technology is applied in association with a chemical treatment step based on the Fenton oxidation, at the corresponding working conditions for highest treatment performance. Thus, new findings on improved SDR performance regarding polluting organic load removal (in dissolved and solid forms) are established.

\section{Materials and Methods}

\subsection{Chemicals and Materials}

All solutions were prepared with distilled water using only high purity chemicals, i.e., $\mathrm{NaOH} 0.1 \mathrm{~N}$ and $\mathrm{H}_{2} \mathrm{SO}_{4} 0.1 \mathrm{~N}$ to adjust the wastewater $\mathrm{pH}, 0.34 \mathrm{mM} \mathrm{FeSO}_{4}$ and $30 \% \mathrm{H}_{2} \mathrm{O}_{2}$ as reagents for advanced Fenton oxidation and indigene bentonite powder (Iasi, Romania) as coagulation adjuvant/discoloration agent.

In the experimental SDR setup, tested in a previous study [15], an industrial WW resulted from 2nd and 3rd steps of rinsing, applied to certain cotton fabrics in the finishing process, was treated.

\subsection{Experimental and Modeling Methodology}

\subsubsection{Experimental Methodology}

All analyses were performed using standardized analytical methods, internationally approved and the main textile effluent characteristics were estimated to be in the range of: 865-4450 HU for initial color, 180-815 FTU for turbidity, 7.12-7.89 for $\mathrm{pH}, 382-930 \mathrm{mg} / \mathrm{L}$ for suspended solid contents, 300-320 $\mathrm{mg} \mathrm{O}_{2} / \mathrm{L}$ for $\mathrm{BOD}_{5}, 560-655 \mathrm{mg} \mathrm{O} / \mathrm{L}$ for COD-Cr and $2.60-3.50 \mathrm{mg} / \mathrm{L}$ for phenol content [15].

- $\quad \mathrm{pH}$ measurement. A Hanna high precision KL-009(I) pH-meter (Hanna Instruments Co., Winsocket, RI, USA) was used for all $\mathrm{pH}$ readings.

- Color determination. A standard method (SR ISO 7887/97) was used where the color is expressed by absorbance under the blank (distilled water) at three different wavelengths, i.e., 436,525 and $620 \mathrm{~nm}$; for industrial wastewaters, the absorbance at $436 \mathrm{~nm}$ is preferred [15,31,32]. Furthermore, the color can be expressed by the Hazen color index (i.e., an absorbance value of 0.069 at $456 \mathrm{~nm}$ corresponds to 50 Hazen units (HU)) [32].

- Suspended solids and turbidity determination. All measurements were directly completed using DR/2000 Direct Reading Spectrophotometer at $630 \mathrm{~nm}$ (in $\mathrm{mg} / \mathrm{L}$ ) for suspended solids content and at $450 \mathrm{~nm}$ (in FTU) for turbidity under a blank with distilled water.

- All other effluent characteristics (e.g., $\mathrm{COD}_{\mathrm{Cr}}, \mathrm{BOD}_{5}$, phenols) were analyzed by using specific standard analysis methods described in other author reports and standards catalogue $[15,26,32]$.

\subsubsection{Modeling Methodology}

The dataset contains a rather small number of instances, i.e., 32 for turbidity and 56 for color (absorbance) removal, including values for disc rotational speed, flowrate, $\mathrm{pH}$ and working time. Therefore, the data was augmented as a pre-processing step before the application of the machine learning algorithms. The following procedure was applied for each instance. Let $v$ be the original value of an attribute. In the augmented dataset, the attribute value was slightly changed in a random manner. $v \prime=v \cdot(r \cdot 0.2+0.9)$, where $r$ is 
a uniform random number between 0 and $1: r \sim U(0,1)$. Thus, in the augmentation process, each input value was changed to a random value between 0.9 and 1.1 of the original value. The output value of the instance was kept unmodified. The augmentation increased the size of the dataset by a factor of 10 for both removal problems (solids and color).

The actual modeling was achieved by several well-established regression methods, such as support vector machine (SVM) [27], M5Rules [28], random forest [29] and linear regression, the latter only as a baseline for comparison.

For all experiments, the Weka [30] machine learning algorithm suite was used.

\subsection{Experimental Laboratory SDR Setup}

The experimental setup includes a $20 \mathrm{~cm}$ diameter acrylic spinning disc within a case, an electric motor, a centrifugal pump, a collecting tank, a flowmeter with an adjustable tap. All the test section design characteristics have been described in a previous paper [15]. Prior to the spinning disc feeding, the effluent was treated with bentonite $(2 \mathrm{~g} / \mathrm{L}$ concentration, established, based on preliminary lab measurements, to render an asymptotic value for turbidity and color removals of less than $40 \%$ and respectively, $20 \%$ ). The effluent samples coming from the spinning disc were collected for spectral measurements using a DR/2000 Direct Reading Spectrophotometer (HACH Company) in order to establish the indicators of interest, turbidity and color. Based on the obtained experimental data, the removal efficiency (\%), $R$, was calculated using the Equation (1):

$$
R[\%]=\left[\left(C_{i}-C_{f}\right) \cdot 100 / C_{i}\right]
$$

With $C_{i}$, the studied quality indicator initial value $(\mathrm{mg} / \mathrm{L}$, or FTU, or absorbance value) and $C_{f}$, the studied quality indicator value measured at a specific time or final $(\mathrm{mg} / \mathrm{L}$, or FTU, or absorbance value).

\subsection{Advanced Fenton Oxidation $\left(\mathrm{Fe}^{2+} / \mathrm{H}_{2} \mathrm{O}_{2}\right)$ Methodology}

The Fenton oxidation (FO) process was applied in the SDR experimental setup, on real textile wastewater, using as the main oxidizing agent, $\mathrm{H}_{2} \mathrm{O}_{2}(30 \%)$ activated by $\mathrm{FeSO}_{4}$ (stock solution of $0.34 \mathrm{mmol} / \mathrm{L}$ ), to form hydroxyl radicals (HO-) (stronger oxidants than $\mathrm{H}_{2} \mathrm{O}_{2}$ ). Different operating conditions were investigated, including different values of $\mathrm{pH}(2.5-5.5)$, addition of certain volumes of $\mathrm{H}_{2} \mathrm{O}_{2}(30-50 \mathrm{~mL})$ and $\mathrm{FeSO}_{4}(50-90 \mathrm{~mL})$, at a constant temperature $\left(\mathrm{t}=20^{\circ} \mathrm{C} \pm 3^{\circ} \mathrm{C}\right)$.

After processing, the efficiency of this mixed SDR and FO treatment in terms of suspended solids or colloidal solids (turbidity) and color removal was evaluated.

\section{Results}

At the time of the experiments, the studied textile WW resulted from an indigene (Iasi, Romania) textile company that manufactures cotton fabrics colored from yellow to red (with a dyeing bath stuff formulation based on two azo dyes, Rosso Kemazol RB and Arancio Kemazol 3R, and Remapon FRD as binding agent) (textile wastewater characteristics presented in other reports) $[24,25,31]$. For the real textile wastewaters, certain performances were obtained by applying different treatment processes (e.g., adsorption on activated carbon or different 'low cost' adsorptive materials as sawdust, coal ashes, residual biomass; different advanced oxidative processes (AOPs) such as Fenton oxidation (FO) $\left(\mathrm{Fe}^{2+} / \mathrm{H}_{2} \mathrm{O}_{2}\right.$ ), catalytic wet peroxide oxidation (CWPO) (zeolites/metal oxides of transitional metal species- $\left.\mathrm{M}^{\mathrm{n}+} / \mathrm{H}_{2} \mathrm{O}_{2}\right)$, photo-Fenton (photo-FO) $\left(\mathrm{Fe}^{2+} / \mathrm{H}_{2} \mathrm{O}_{2} / \mathrm{UV}\right)$ or Fenton-like oxidation (transitional/high valence metallic species- $\mathrm{M}^{\mathrm{n}+} / \mathrm{H}_{2} \mathrm{O}_{2}$ ), photo-decomposition of hydrogen peroxide $\left(\mathrm{H}_{2} \mathrm{O}_{2} / \mathrm{UV}\right)$, photolysis of ozone $\left(\mathrm{O}_{3} / \mathrm{UV}\right)$, sonolysis, radiolytic treatment; coagulation-flocculation (CF) in association with sedimentation or filtration etc., individually or mixed applied $[14,25]$, but not in the case of SD and FO technology, applied in the proposed mono-block experimental setup. 
The FO process applied for textile wastewaters offers many advantages such as short oxidation times, simplicity in destroying polluting species, stability in the treatment of a wide range of substances, relatively small quantities of newly formed precipitates or sludge, no requirement for additional special equipment and high proficiency. Thus, the FO was selected to be applied in the same SDR setup for improved treatment performance.

\subsection{Effluent Treatment Performance Using Laboratory SD Technology Experimental Setup}

The textile WW quality indicators measured at five different feeding flowrates of 10, 15, 20, 25 and $30 \mathrm{~L} / \mathrm{h}$ and seven different disc rotating speeds, namely 100, 250, 400, 550, 850, 1200 and $1500 \mathrm{rpm}$, were investigated in order to establish how efficient the SD technology in WW treatment can be.

Values of the measured textile WW color (HU, based on A456) at three different disc rotating speeds of 100, 300 and respectively, $500 \mathrm{rpm}$, at a WW flowrate of $10 \mathrm{~L} / \mathrm{h}$ (Figure 1a) and respectively, of $30 \mathrm{~L} / \mathrm{h}$ (Figure 1b), indicated decreasing trends. The slopes were steeper or gentler depending on the rotating disc speed and the textile WW flowrate, proving the spinning disc technology effectiveness.
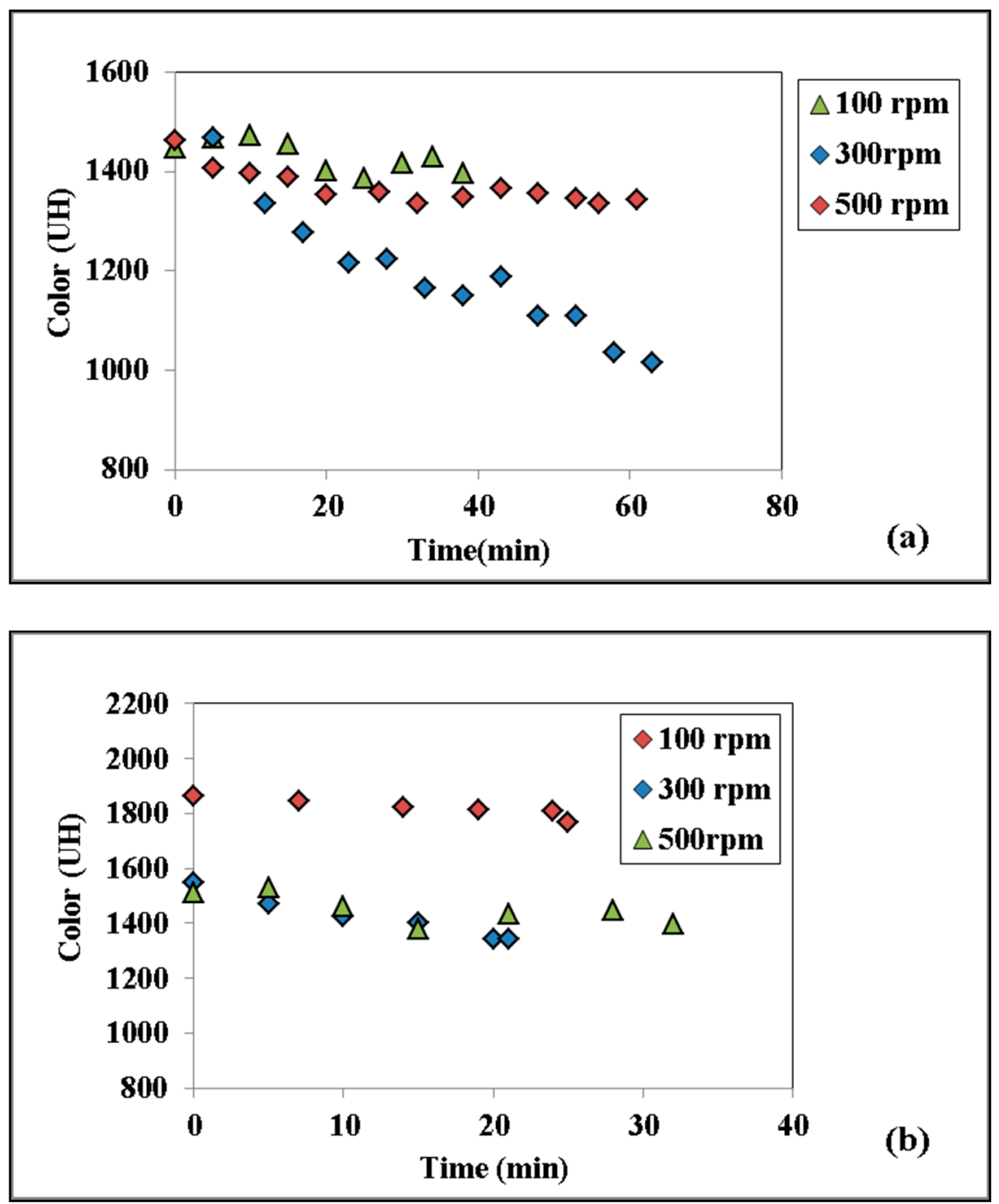

Figure 1. Textile WW color variation in time at three different rotational speeds and a WW flowrate of (a) $10 \mathrm{~L} / \mathrm{h},(\mathbf{b}) 30 \mathrm{~L} / \mathrm{h}$.

Additionally, the WW turbidity variation in time, at a WW flowrate of $15 \mathrm{~L} / \mathrm{h}$, and respectively, at $25 \mathrm{~L} / \mathrm{h}$, both at three different disc rotational speed values, is presented in 
Figure 2a,b and indicates similar decreasing trends, which demonstrates the SD technology efficiency within the laboratory experimental setup.
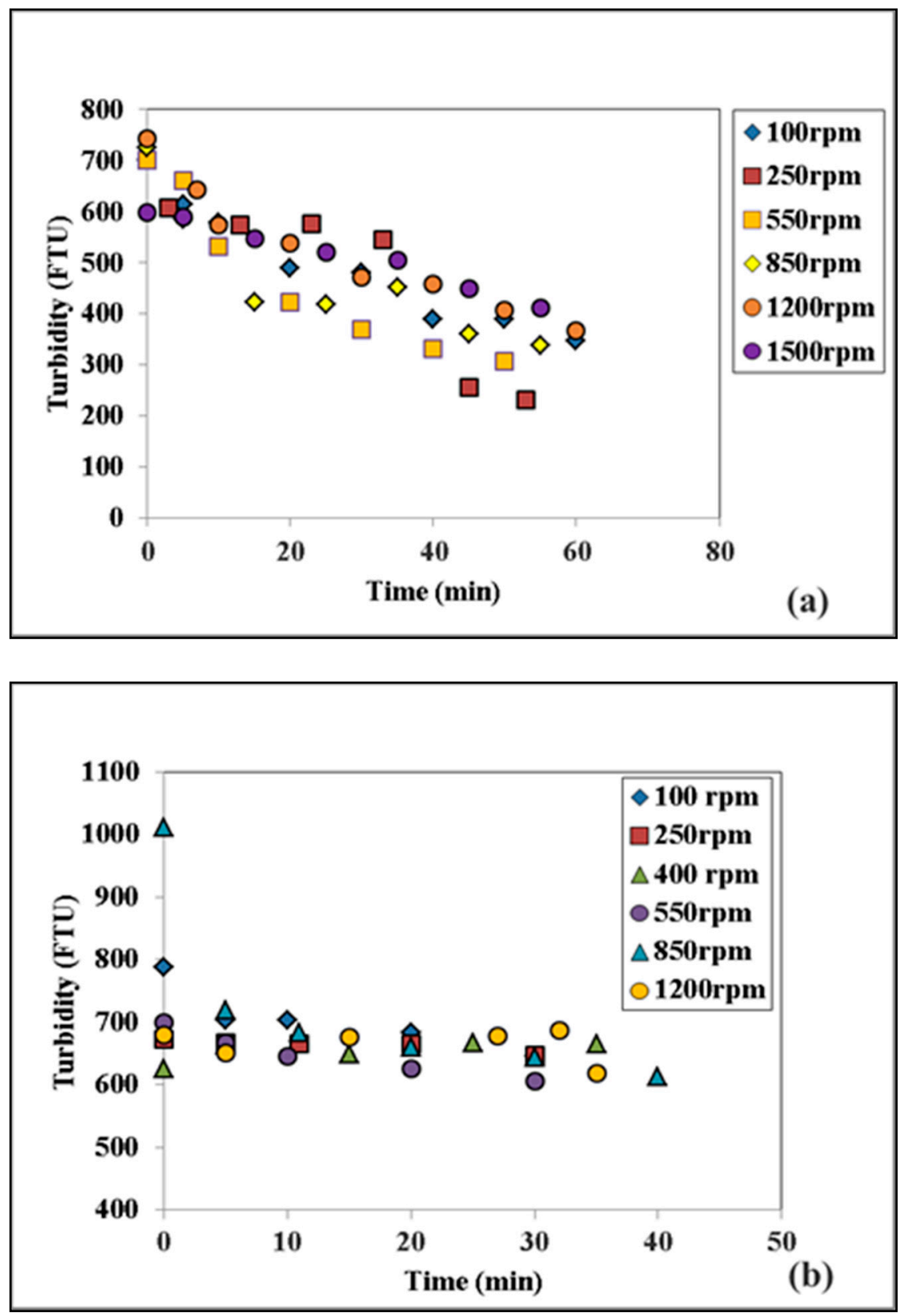

Figure 2. Textile WW turbidity variation in time at three different rotating speeds and a WW flow rate of (a) $15 \mathrm{~L} / \mathrm{h},(\mathbf{b}) 25 \mathrm{~L} / \mathrm{h}$.

Once the time variation of the two examined WW quality indicators was obtained, the removal efficiency was calculated using the Equation (1) and afterwards, graphically represented to find the most lucrative WW flowrate and disc rotating speed values, for which the highest removal values are achieved. Following, the WW flowrate influence, at constant disc rotating speeds, and also the disc rotating speed influence, at constant WW flowrates, on turbidity removal and discoloration are discussed. 
3.1.1. WW Flowrate Effect on the Treatment Efficiency Using the Laboratory SD Setup

Preliminary studies indicated higher removal values for the WW turbidity than for the WW color [32]. Thus, larger ranges of the effluent flowrate and disc rotational speed were investigated to assess the SD effectiveness with respect to the WW turbidity.

The turbidity removal at different WW flowrates and constant disc rotational speed values has been calculated. Figure $3 a-d$ presents some of the data related to the increasing trends of turbidity removal in time, at different disc rotating speeds and liquid flow rates. Other graphs sustaining similar trends are included in the Supplementary Data Section (i.e., Figure S1a-c). The maximum values obtained at specific working conditions are depicted in Table 1, while the other data for the remaining investigated working conditions are available in the Supplementary Data Section (Table S1). All the acquired values are relatively high, with the highest registered turbidity removal of $65.69 \%$.

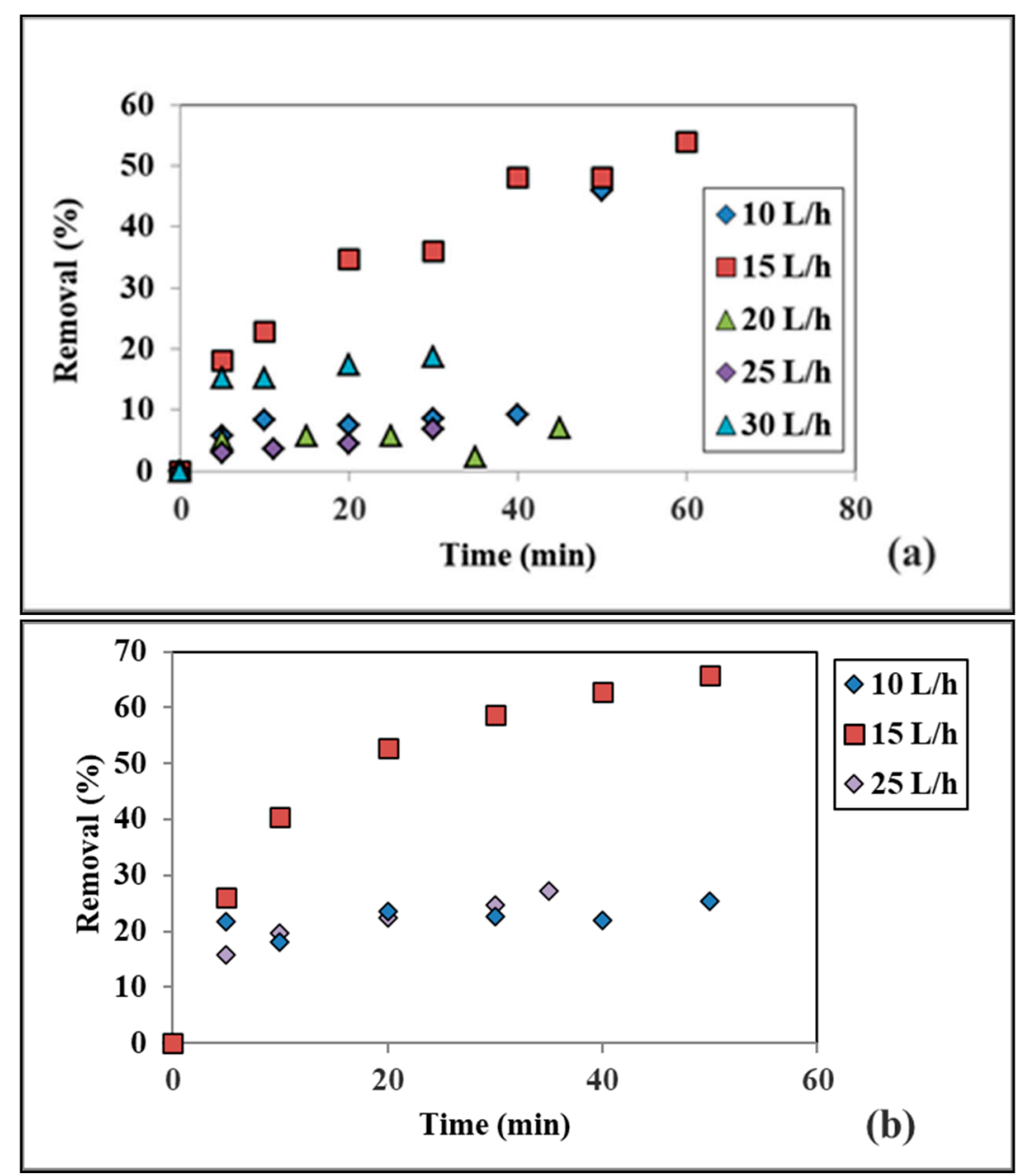

Figure 3. Cont. 


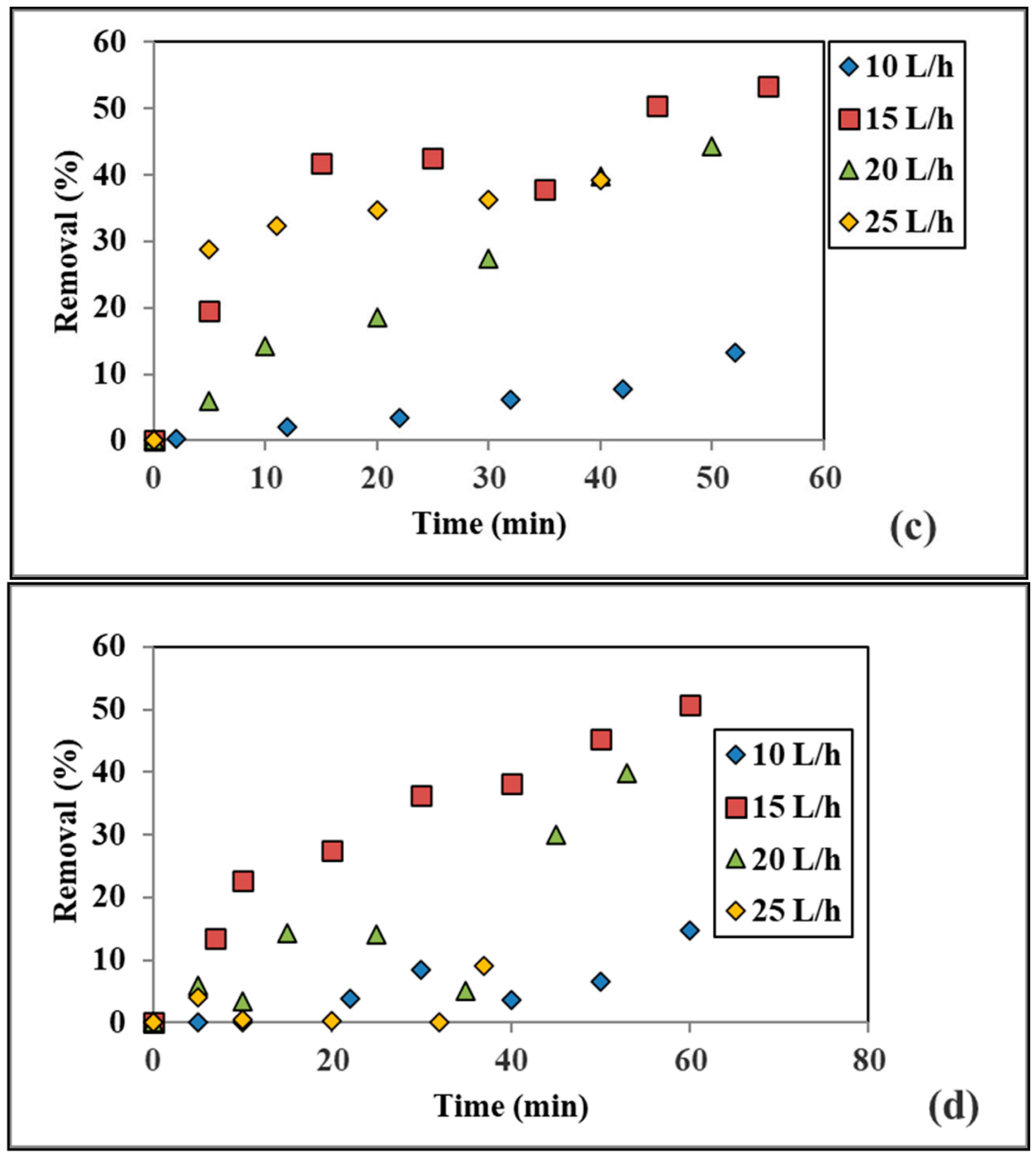

Figure 3. Turbidity removal dependence on WW flowrate at different disc rotational speeds: (a) $100 \mathrm{rpm}$, (b) $550 \mathrm{rpm}$, (c) $850 \mathrm{rpm}$, (d) $1200 \mathrm{rpm}$.

Table 1. Maximum values of turbidity removals and the corresponding investigated SD operating parameter values.

\begin{tabular}{cccc}
\hline $\begin{array}{c}\text { Rotating Speed } \\
{[\mathbf{r p m}]}\end{array}$ & $\begin{array}{c}\text { Flow Rate } \\
{[\mathrm{L} / \mathrm{h}]}\end{array}$ & $\begin{array}{c}\text { TurbidityRemoval } \\
{[\%]}\end{array}$ & $\begin{array}{c}\text { Time Period } \\
{[\mathbf{m i n}]}\end{array}$ \\
\hline 100 & 15 & 53.86 & 60 \\
\hline 250 & 10 & 45.42 & 60 \\
\hline 400 & 10 & 40.13 & 60 \\
\hline 550 & 15 & 65.69 & 50 \\
\hline 850 & 15 & 53.31 & 55 \\
\hline 1200 & 15 & 50.67 & 60 \\
\hline 1500 & 15 & 58.03 & 25 \\
\hline
\end{tabular}

For two different effluent flowrates supplied on the spinning disc rotating at a constant rate, the discoloration is represented in Figure $4 \mathrm{a}-\mathrm{c}$. One can observe that the highest removal value is of $43.3 \%$ at $300 \mathrm{rpm}$ and $10 \mathrm{~L} / \mathrm{h}$, the slope of the graphs is higher than for the other investigated conditions which suggests higher rates of removal. 

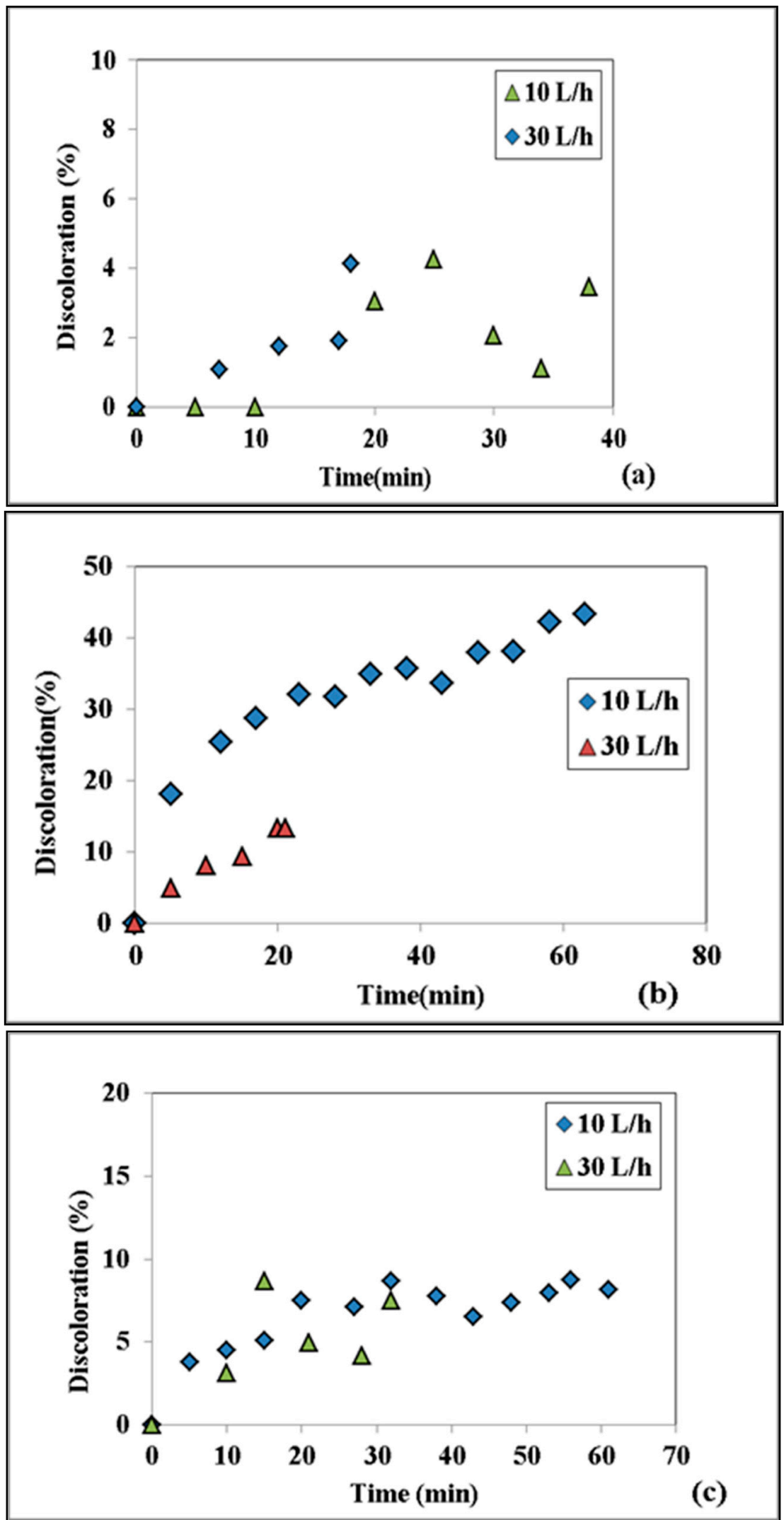

(c)

Figure 4. Color removal dependence on WW flowrate at different disc rotational speeds: (a) $100 \mathrm{rpm}$, (b) $300 \mathrm{rpm}$, (c) $500 \mathrm{rpm}$. 
The maximum WW color removal values for different flowrates and disc rotational speeds can be accessed in Supplementary Data Section (Table S2). The color removal results suggest the necessity of an additional treatment in order to obtain more satisfactory yields.

In conclusion, the WW flowrate fed on the disc seemed to render the highest removal in terms of turbidity at $15 \mathrm{~L} / \mathrm{h}$, for most of the investigated rotational speeds of $100 \mathrm{rpm}$, $300 \mathrm{rpm}, 550 \mathrm{rpm}, 850 \mathrm{rpm}, 1200 \mathrm{rpm}$ and $1500 \mathrm{rpm}$, while for color, at $10 \mathrm{~L} / \mathrm{h}$ and $300 \mathrm{rpm}$. The highest turbidity removal value of $65.69 \%$ demonstrates that the SD technology can be used as a primary mechanical step for WW treatment. Furthermore, one can observe the increasing trends which suggest that even higher turbidity removal values can be obtained, provided longer working time periods are assured. In this study, the experimental time periods were restrained by the operating energy cost of the SD setup and the volume of textile WW in the laboratory reservoir.

\subsubsection{Disc Rotating Speed Effect on the WW Treatment Efficiency Using Laboratory} SD Setup

The disc rotating speed effect on the SD technology efficiency was established once the variations in time of WW color and turbidity removal were represented, at constant WW flowrates.

Figure 5a-d presents the turbidity removal in the same above-mentioned conditions: seven different disc rotational speeds and five different flowrates. For almost all investigated flowrates, 10, 15, 20 and $25 \mathrm{~L} / \mathrm{h}$, respectively, the largest turbidity removals occurred at the rotational speeds of $250 \mathrm{rpm}, 550 \mathrm{rpm}$, and respectively, $850 \mathrm{rpm}$. At $30 \mathrm{~L} / \mathrm{h}$, no matter the disc rotational speed values, the turbidity removal was not significant, thus the graphs were not included. As previously discussed, higher disc rotational speeds enhance micromixing intensity in the liquid film, as long as the liquid residence times on the disc are large enough. The liquid flowrate fed on the disc has a weaker influence on the shear stress affecting the mixing intensity, thus, for most of the investigated liquid flowrates, the turbidity removals were reasonably good.

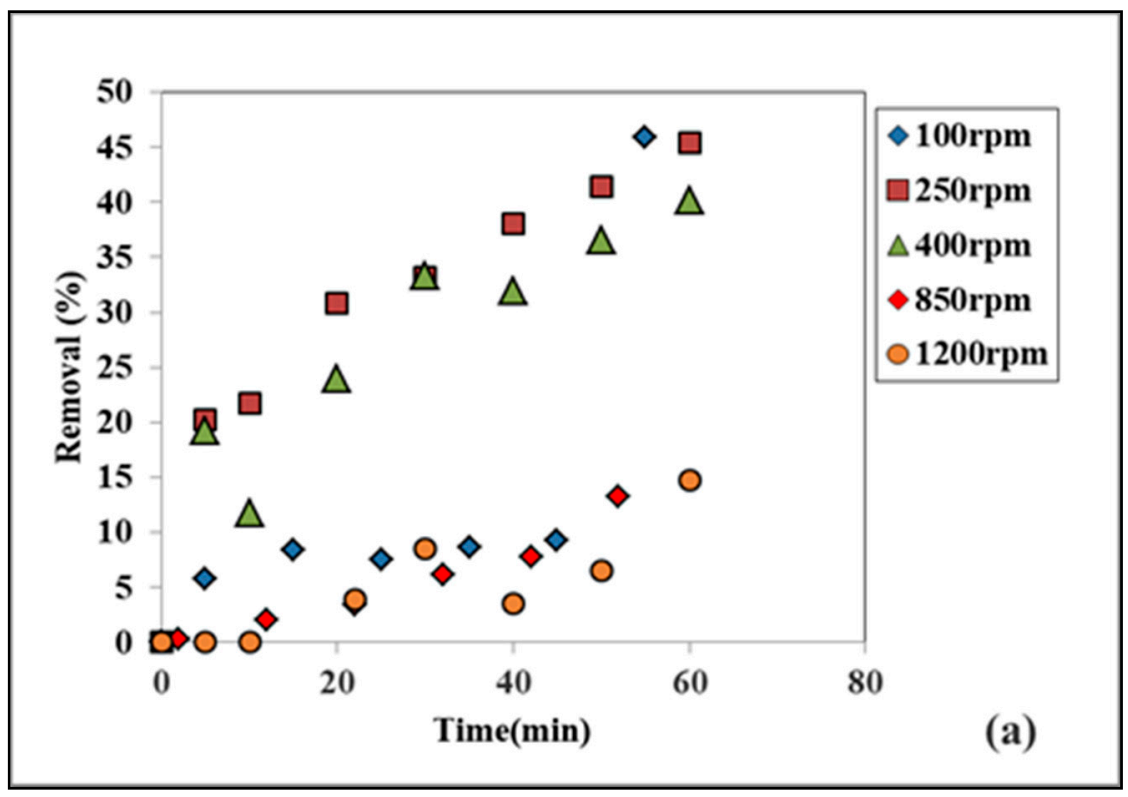

Figure 5. Cont. 

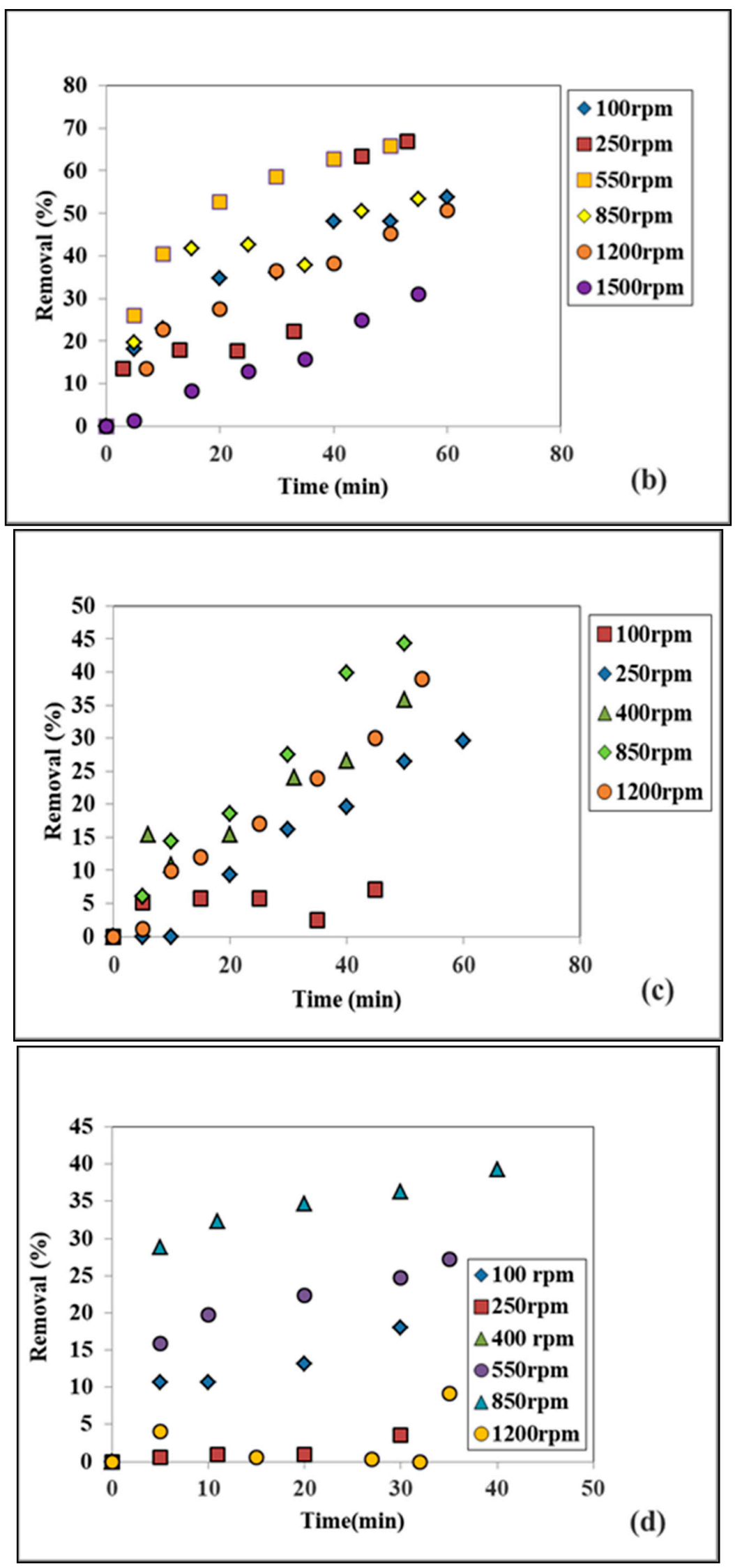

Figure 5. Disc rotating speed effect on turbidity removal, at different effluent flowrates: (a) $10 \mathrm{~L} / \mathrm{h}$, (b) $15 \mathrm{~L} / \mathrm{h},(\mathbf{c}) 20 \mathrm{~L} / \mathrm{h},(\mathbf{d}) 25 \mathrm{~L} / \mathrm{h}$. 
The color removal measured at three distinctive disc rotating speeds and a constant flowrate does not attain values larger than $43.30 \%$ at $300 \mathrm{rpm}$ and $10 \mathrm{~L} / \mathrm{h}$, thus the temporal graphs are included in the Supplementary Data Section (as Figure S2a,b).

All experimental results concerning the maximal efficiency in turbidity with the corresponding disc rotating speed and liquid flow rate are summarized in Table 1 . Some additional data can be found in Supplementary Data (Table S1).

The turbidity removal data were satisfactory, however, the obtained discoloration rates were low, thus, we were enticed to apply additional WW treatments within the same SD laboratory setup in order to decrease further the colored organic and inorganic effluent loads.

\subsection{WW Treatment Improvement by Fenton Oxidation in the Laboratory SD Setup}

The experiments on textile effluent treatment using Fenton's oxidation within the laboratory SDR setup were performed in order to study the WW treatment efficiency expressed by suspended solids (or turbidity, both with closed similarities regarding the time variation) and color removals, considering also the influence of a few operating parameters such as $\mathrm{pH}$, hydrogen peroxide and ferrous sulphate concentrations.

Figure 6A presents discoloration data in time, for different $\mathrm{pH}$ values, when three consecutive circulations of the WW through the laboratory SD setup were performed. One can observe that the color removal by Fenton oxidation was most efficient at a $\mathrm{pH}$ of 2.5 , for all three circulations. At this $\mathrm{pH}$ of 2.5, during the first circulation, the highest removal value was obtained, of $62.83 \%$, after $25 \mathrm{~min}$. However, the discoloration decreased significantly as the $\mathrm{pH}$ value was increased at 3.5, 4.1 and respectively 5.0 , reaching respectively the following maximum values: $36.44 \%, 16.84 \%$ and $19.12 \%$, after 16,10 and respectively, 15 min during the first circulation.

Figure $6 \mathrm{~B}$ presents the suspended solids removal for different $\mathrm{pH}$ values, during three circulations of the textile WW through the experimental laboratory SD setup. The suspended solids removals present similar trends as the discoloration, all maximum values are obtained at $\mathrm{pH}=2.5$, for all three WW circulations, namely of $69.46 \%, 59.49 \%$ and $50.57 \%$, after 25, 50 and $75 \mathrm{~min}$, respectively. As the $\mathrm{pH}$ increases, the suspended solids removal decreases, the lowest values being registered at $\mathrm{pH}$ of 4.1 and 5.0.

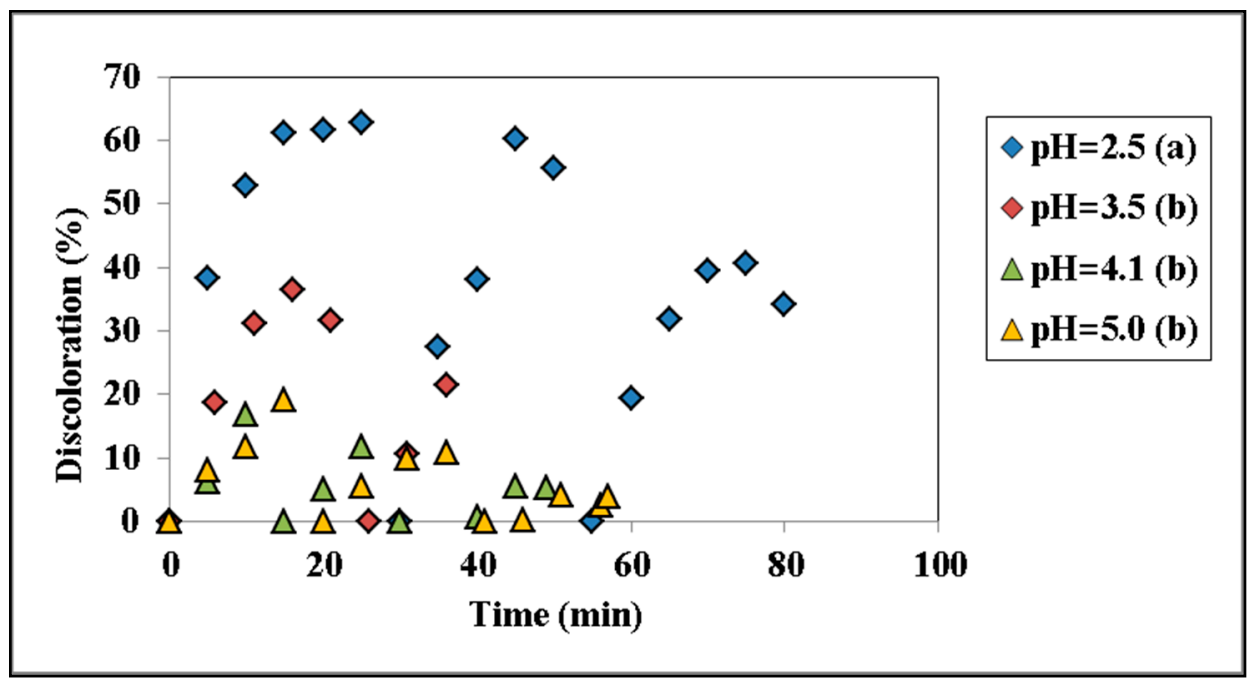

(A)

Figure 6. Cont. 


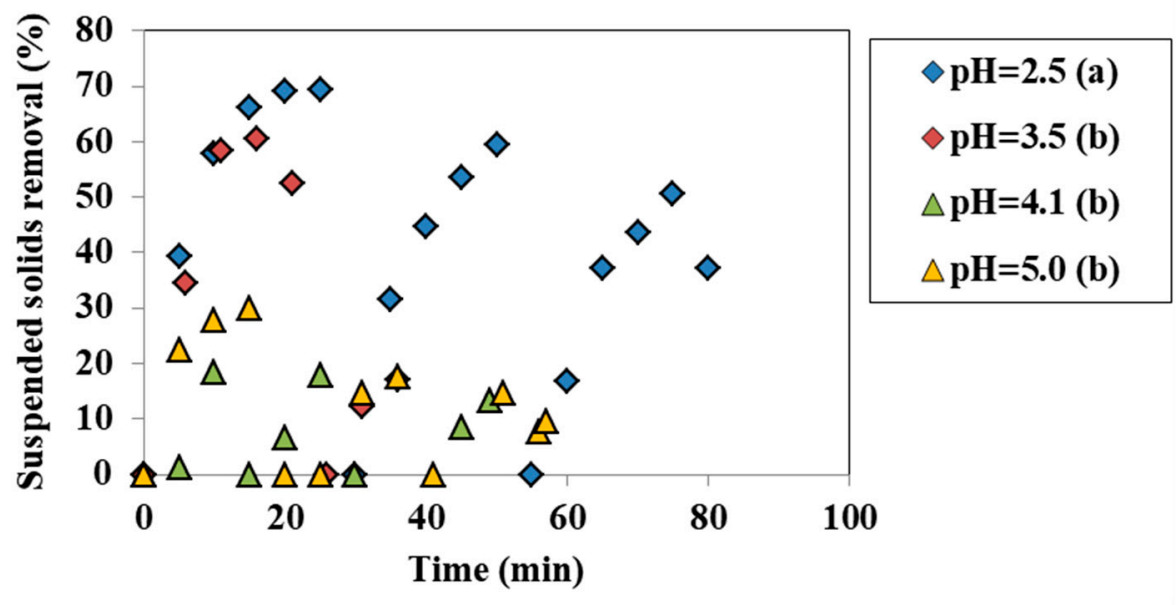

(B)

Figure 6. (A) pH influence on color removal (a) $17 \mathrm{~L} / \mathrm{h}, 100 \mathrm{rpm}$; (b) $20 \mathrm{~L} / \mathrm{h}, 200 \mathrm{rpm}$. Initial operating con-ditions: $\mathrm{C}_{0, \mathrm{H} 2 \mathrm{O} 2}=14.91 \mathrm{mM} ; \mathrm{C}_{0, \mathrm{Fe} 2+}=0.10 \mathrm{mM} \mathrm{FeSO}_{4}$. (B) $\mathrm{pH}$ influence on suspended solids removal (a) $17 \mathrm{~L} / \mathrm{h}, 100 \mathrm{rpm}$; (b) $20 \mathrm{~L} / \mathrm{h}, 200 \mathrm{rpm}$. Initial operating conditions: $\mathrm{C}_{0, \mathrm{H} 2 \mathrm{O} 2}=14.91 \mathrm{mM}$; $\mathrm{C}_{0, \mathrm{Fe} 2+}=0.10 \mathrm{mM} \mathrm{FeSO}_{4}$.

The treatment efficiency in terms of color and suspended solids or turbidity decreases with each circulation in the SD setup, as shown in Figure 6A,B, mainly due to the suspended solids or turbidity and color decreasing initial values. These trends comply with other reported results that establish that the treatment efficiencies for decreasing values of WW color and suspended solids (turbidity) were decreasing [33,34], and consequently, other competitive collisions and ionic/molecular species adsorption in treated wastewater were minimized.

The maximum removal values for both color and suspended solids, at different $\mathrm{pH}$ values, are presented in Table 2.

Table 2. The maximum color and suspended solids removals, at different $\mathrm{pH}$ values at investigated SD operating parameter values.

\begin{tabular}{|c|c|c|c|c|}
\hline $\mathrm{pH}$ & Circulation No. & $\begin{array}{c}\text { Color } \\
\text { Removal }^{1}[\%]\end{array}$ & $\begin{array}{c}\text { SS Removal }^{2} \\
{[\%]}\end{array}$ & $\begin{array}{c}\text { Time Period } \\
{[\text { [min] }}\end{array}$ \\
\hline \multirow{3}{*}{2.5} & I & 62.84 & 69.46 & $25 ; 25$ \\
\hline & II & 60.08 & 59.49 & $50 ; 50$ \\
\hline & III & 40.66 & 50.57 & $75 ; 75$ \\
\hline \multirow{2}{*}{3.5} & I & 36.44 & 60.52 & $16 ; 16$ \\
\hline & II & 21.36 & 17.03 & $36 ; 36$ \\
\hline \multirow{3}{*}{4.1} & I & 16.84 & 18.52 & $10 ; 10$ \\
\hline & II & 11.81 & 17.77 & $25 ; 25$ \\
\hline & III & 5.49 & 14.70 & $45 ; 51$ \\
\hline \multirow{3}{*}{5.0} & I & 19.12 & 30.06 & $15 ; 15$ \\
\hline & II & 10.77 & 17.67 & $36 ; 36$ \\
\hline & III & 4.08 & 14.73 & $51 ; 51$ \\
\hline
\end{tabular}

1 color removal and ${ }^{2}$ SS removal and the corresponding time periods (for color removal-first value and for SS removal -second value). 
The efficiency of hydrogen peroxide concentration on color removal is represented in Figure 7A for all three WW circulations through the experimental laboratory SD setup. One can observe that at a hydrogen peroxide concentration of $14.91 \mathrm{mM}$, the discoloration attains maximum values for the first and second SD setup circulations, of $62.83 \%$ and respectively, of $60.08 \%$, after 25 and $45 \mathrm{~min}$, respectively. An increase in hydrogen peroxide concentration from $14.91 \mathrm{mM}$ to $24.86 \mathrm{mM}$ reduces significantly the color removal.

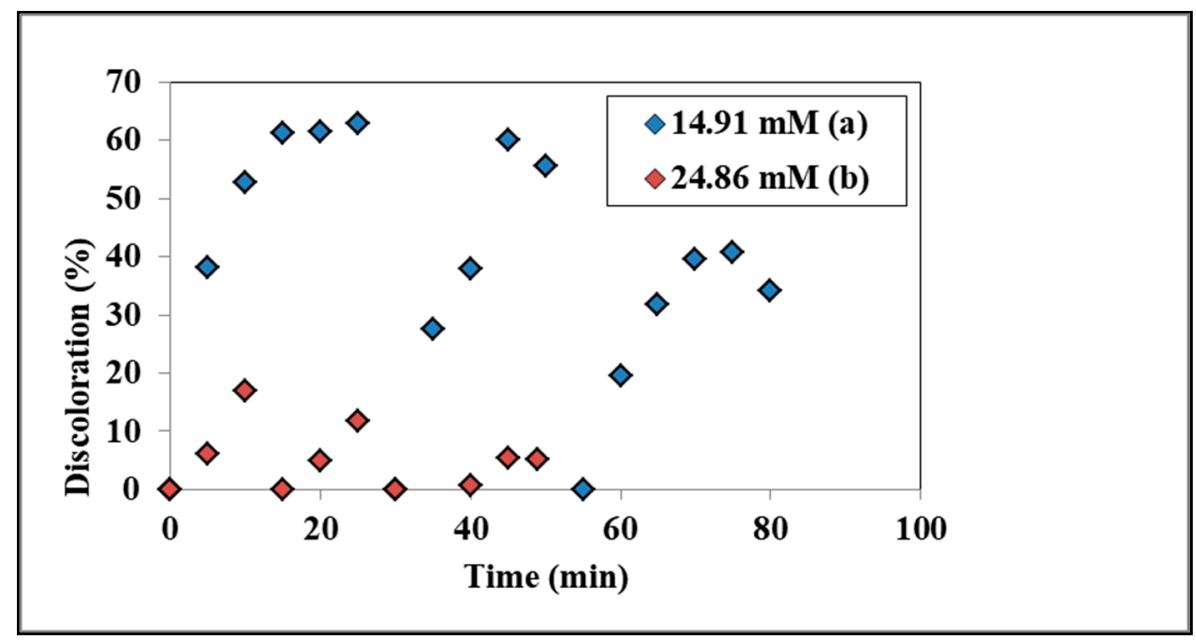

(A)

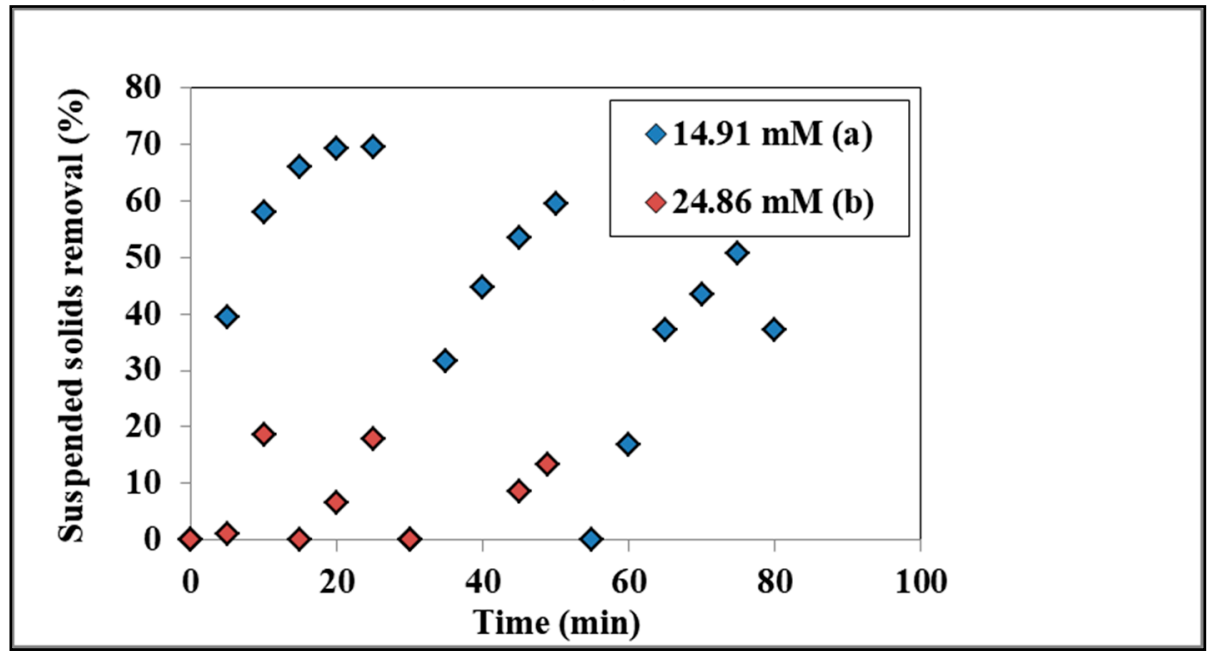

(B)

Figure 7. (A) Hydrogen peroxide concentration influence on discoloration (a) $17 \mathrm{~L} / \mathrm{h}, 100 \mathrm{rpm}$; (b) $20 \mathrm{~L} / \mathrm{h}, 200 \mathrm{rpm}$. Initial operating conditions: $\mathrm{pH}=3.50 ; \mathrm{C}_{0, \mathrm{Fe} 2+}=0.10 \mathrm{mM} \mathrm{FeSO}_{4}$. (B) Hydrogen peroxide con-centration influence on suspended solids removal. (a) $17 \mathrm{~L} / \mathrm{h}, 100 \mathrm{rpm}$; (b) $20 \mathrm{~L} / \mathrm{h}$, $200 \mathrm{rpm}$. Initial operating conditions: $\mathrm{pH}=3.50 ; \mathrm{C}_{0, \mathrm{Fe} 2+}=0.10 \mathrm{mM} \mathrm{FeSO}_{4}$.

The hydrogen peroxide concentration influence on the suspended solids removal, for the three textile effluent circulations through the laboratory SD setup is shown in Figure 7B. The performed removals reach the highest values for the lower hydrogen peroxide concentration, namely of $14.91 \mathrm{mM}$ and the maximum values decrease with each circulation. This can be explained by the fact that at low hydrogen peroxide concentration, $\mathrm{H}_{2} \mathrm{O}_{2}$ acts as an initiator of hydroxyl radicals, thus, producing the organics decomposition (WW discoloration) according to mechanisms described by other authors reports [24] and on the contrary, at high hydrogen peroxide concentrations, $\mathrm{H}_{2} \mathrm{O}_{2}$ acts as an $\mathrm{OH} \bullet$ scavenger, thus the organics decomposition is not possible. In order for the $\mathrm{H}_{2} \mathrm{O}_{2}$ decomposition to 
produce the maximum amount of hydroxyl radicals, it is recommended to be performed in the presence of an acid aqueous medium $(\mathrm{pH}=2.5-3.5)$.

The overall Fenton oxidation process can be simplified as in Equation (2) [24,31].

$$
2 \mathrm{Fe}^{2+}+\mathrm{H}_{2} \mathrm{O}_{2}+2 \mathrm{H}^{+} \rightarrow 2 \mathrm{Fe}^{3+}+2 \mathrm{H}_{2} \mathrm{O}
$$

All obtained maximum values for discoloration and suspended solids removal, at the two investigated hydrogen peroxide concentrations of $14.91 \mathrm{mM}$ and respectively 24.86 $\mathrm{mM}$, are presented in Table 2, for the $\mathrm{pH}$ values of 2.5 and respectively, 4.1 (combined radicalic and non-radicalic mechanism).

The ferrous sulfate concentration influence on color removal, represented in Figure 8A for the three WW circulations through the experimental laboratory SD setup, indicates that the discoloration attains the highest values for the first and second SD setup circulations, of $62.84 \%$ and respectively, of $60.08 \%$, after 25 and respectively, $45 \mathrm{~min}$, at $0.10 \mathrm{mM} \mathrm{FeSO}$. An increase in iron (II) sulfate concentration from $0.10 \mathrm{mM}$ to $0.14 \mathrm{mM}$ reduces the color removal, the largest removal value being of $36.44 \%$, after $16 \mathrm{~min}$, for the first circulation (Table 2, $\mathrm{pH}=3.5$ ). Furthermore, $\mathrm{FeSO}_{4}$ concentration increase at $0.18 \mathrm{mM}$ determines a decrease of the maximum removal, at the first circulation, to a value of $19.12 \%$ (Table 2, $\mathrm{pH}=5.0$.

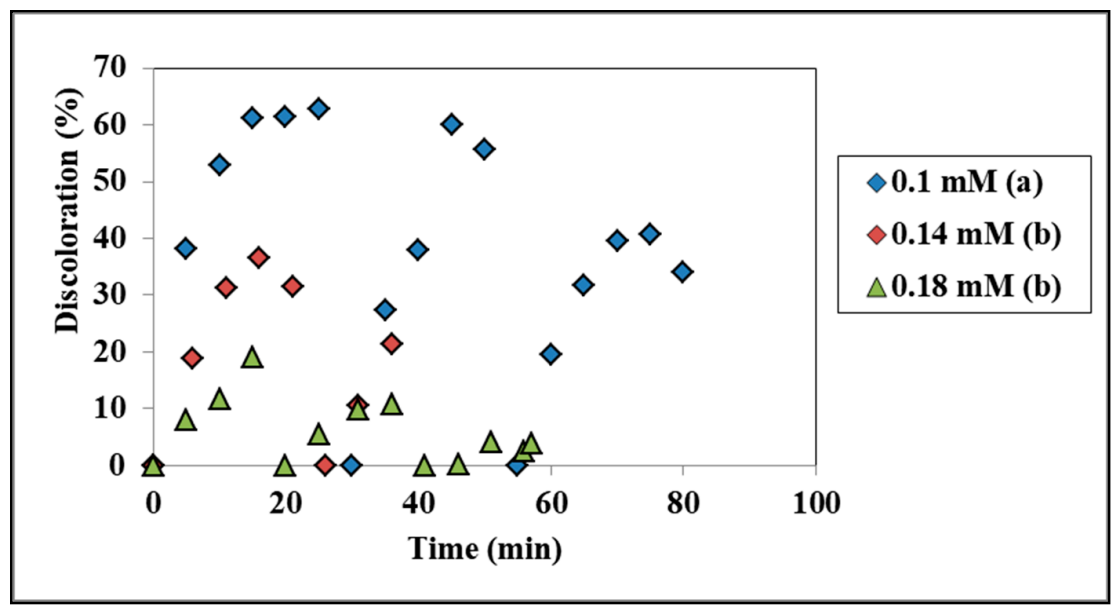

(A)

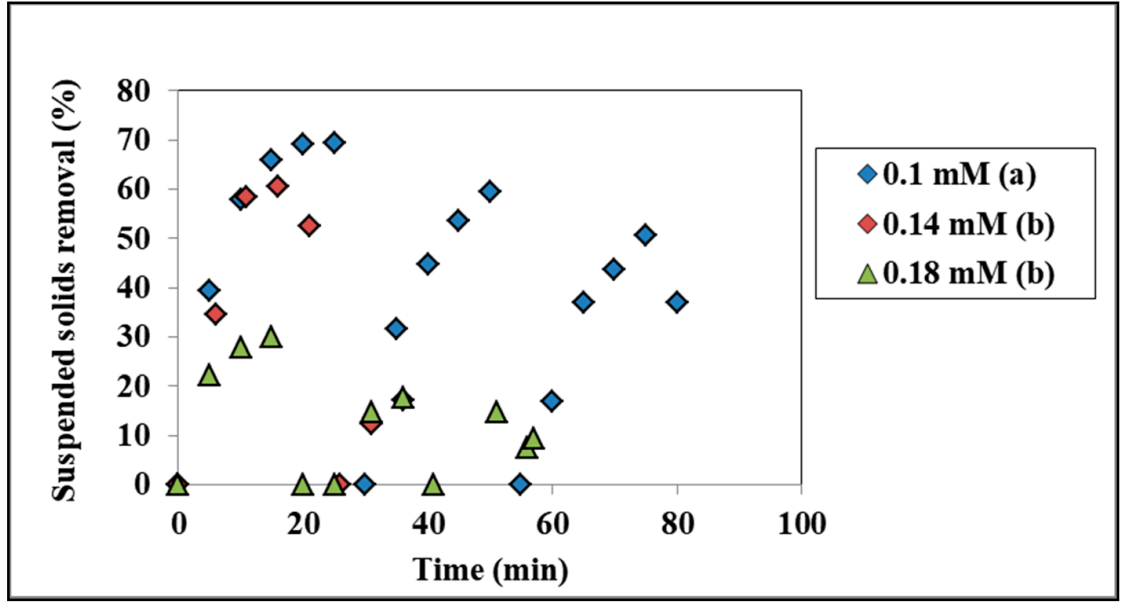

(B)

Figure 8. (A) $\mathrm{FeSO}_{4}$ concentration influence on $W W$ discoloration. (a) $17 \mathrm{~L} / \mathrm{h}, 100 \mathrm{rpm}$; (b) $20 \mathrm{~L} / \mathrm{h}$, $200 \mathrm{rpm}$. Initial operating conditions: $\mathrm{C}_{0, \mathrm{H} 2 \mathrm{O} 2}=24.86 \mathrm{mM} ; \mathrm{pH}=4.10$. (B) $\mathrm{FeSO}_{4}$ concentration influence on suspended solids removal. (a) $17 \mathrm{~L} / \mathrm{h}, 100 \mathrm{rpm}$; (b) $20 \mathrm{~L} / \mathrm{h}$, $200 \mathrm{rpm}$. Initial operating conditions: $\mathrm{C}_{0, \mathrm{H} 2 \mathrm{O} 2}=24.86 \mathrm{mM} ; \mathrm{pH}=4.10$. 
The ferrous sulfate concentration influence on the suspended solids removal, for the three textile effluent circulations through the laboratory SD setup, is represented in Figure 8B. The obtained removals attain the highest values for the lowest $\mathrm{FeSO}_{4}$ concentration, namely of $0.10 \mathrm{mM}$, and the maximum values decrease with each circulation. The higher the iron sulfate concentration, the lower the solids removal.

All obtained maximum values for discoloration and suspended solids removal, at the three investigated ferrous sulfate concentrations of $0.10 \mathrm{mM}, 0.14 \mathrm{mM}$ and respectively $0.18 \mathrm{mM}$, are presented in Table 2, for the $\mathrm{pH}$ values of 2.5, 3.5 and respectively, 5.0.

In conclusion, the Fenton oxidation applied to textile effluents, provided the highest color and suspended solids removals at $\mathrm{pH}=2.5$, a hydrogen peroxide concentration of $14.91 \mathrm{mM}$ and an iron (II) sulfate of $0.10 \mathrm{mM}$.

After this combined SD circulation and FO process achieved in the laboratory SD setup, the treated textile effluent must mandatorily undertake, before final discharge in aquatic receptors, an adsorption step (usually with granular activated carbon or an efficient 'low cost' adsorbent) $[34,35]$ to retain the residual hydrogen peroxide (in a closed contact filter/tank) and even further, a neutralization step (the final discharge must have a $\mathrm{pH}$ in the range of 6.5-8.5) in order to comply with the imposed legislative quality norms. Furthermore, the separated solids at the treated WW collecting tank bottom can be used for composites manufacturing after extraction of useful compounds or its inactivation.

\subsection{Modeling and Optimization Study \\ 3.3.1. Modeling Data}

The different regression models are compared using 10-fold cross-validation on the augmented dataset. Cross-validation is a de facto standard for assessing the quality of a model. The dataset is divided into $n$ (e.g., $n=10$ ) equal groups and $\mathrm{n}$ iterations are performed. In each iteration $i$, the group $I$ is considered as the testing set and the remaining $n-1$ groups are considered together as forming the training set. Thus, in each iteration, the test set changes, and the whole dataset acts both as the training set, and the testing set. Finally, a quality metric is applied to the union of these $n$ test sets.

In our case, the correlation coefficient $r$ has been selected as the quality metric. A good model will produce a high correlation coefficient, close to 1 .

In Table 3, the results for the first dataset, i.e., turbidity removal as function of disc rotational speed, flowrate and working time, are presented, for the two user-defined parameters, $\sigma$ and $\omega$ in PUK kernel.

Table 3. Cross-validation results for turbidity removal.

\begin{tabular}{cc}
\hline Model & $r$ \\
\hline SVM, PUK, $\sigma=\omega=1, C=100$ & $\mathbf{0 . 9 7 4 9}$ \\
SVM, PUK, $\sigma=\omega=1, C=1$ & 0.9509 \\
SVM, PUK, $C=1.036, \sigma=1.32, \omega=0.64$ & 0.9419 \\
SVM, PUK, $C=100, \sigma=1.32, \omega=0.64$ & 0.9744 \\
SVM, PUK, $\sigma=\omega=1, C=1000$ & 0.9665 \\
\hline Linear Regression & 0.5962 \\
M5Rules, $n_{i}=4$ & 0.9332 \\
Random Forest, $n_{t}=100$ & 0.9641 \\
\hline
\end{tabular}

Support vector machines are applied with different parameters for regression. Although polynomial and RBF kernels were also tried, the PUK kernel (Pearson VII functionbased universal kernel) [36] provided the best results. The non-integer values of the $\sigma$ and $\omega$ parameters, which define the width and the tailing shape of the Pearson VII function, were computed with the Auto-Weka feature, where the program searches for the best parameter configuration. However, these settings do not seem to bring an improvement over the empirically selected values. The other parameters of the algorithms in Table 3 are: $n_{i}$ - the minimum number of instances, and $n_{t}$-the number of trees. 
From this table, one can conclude that the best performance is obtained by SVM with a medium value of the cost parameter $(C=100)$. The $C$ parameter controls the tolerated errors, the soft margin of the model.

The second problem, the numeric value corresponding to the absorbance, as color indicator, was addressed in two variants. Since most instances have the same $\mathrm{pH}$ value, the first variant considers only those instances, with the $\mathrm{pH}$ attribute removed altogether, i.e., 3 inputs (disc rotational speed, liquid flowrate and working time) and 1 output (absorbance removal or discoloration) [37]. The second variant considers the whole dataset with 4 inputs and 1 output, to the three entries listed above adding $\mathrm{pH}$.

Table 4 presents the results for the first variant. In this case, one can see that the same SVM configuration yields the best results. The same situation holds for the second variant, displayed in Table 5.

Table 4. Cross-validation results for color removal/discoloration (without $\mathrm{pH}$ influence).

\begin{tabular}{lc}
\multicolumn{1}{c}{ Model } & $\boldsymbol{r}$ \\
\hline SVM, PUK, $\sigma=\omega=1, C=100$ & $\mathbf{0 . 9 3 6 7}$ \\
SVM, PUK, $\sigma=\omega=1, C=1$ & 0.8499 \\
SVM, PUK, $\sigma=\omega=1, C=1000$ & 0.9351 \\
Linear Regression & 0.4684 \\
M5Rules, $n_{i}=4$ & 0.8522 \\
Random Forest, $n_{t}=100$ & 0.9285 \\
\hline
\end{tabular}

Table 5. Cross-validation results for color removal/discoloration (with $\mathrm{pH}$ influence).

\begin{tabular}{lc}
\hline \multicolumn{1}{c}{ Model } & $\boldsymbol{r}$ \\
\hline SVM, PUK, $\sigma=\omega=1, C=100$ & $\mathbf{0 . 9 2 1 9}$ \\
SVM, PUK, $\sigma=\omega=1, C=1$ & 0.7484 \\
SVM, PUK, $\sigma=\omega=1, C=1000$ & 0.9213 \\
Linear Regression & 0.3014 \\
M5Rules, $n_{i}=4$ & 0.4939 \\
Random Forest, $n_{t}=100$ & 0.9154 \\
\hline
\end{tabular}

An important point is that the linear regression gives poor correlations in all three scenarios.

Figure 9 shows the comparison between experimental and simulation results for turbidity removal, indicating a good agreement represented by the determination coefficient value of $r=0.9944$. For WW discoloration, in regular SD setup and respectively, Fenton SD system, similar values for $r$ of 0.9839 and respectively, 0.9955 , were obtained.

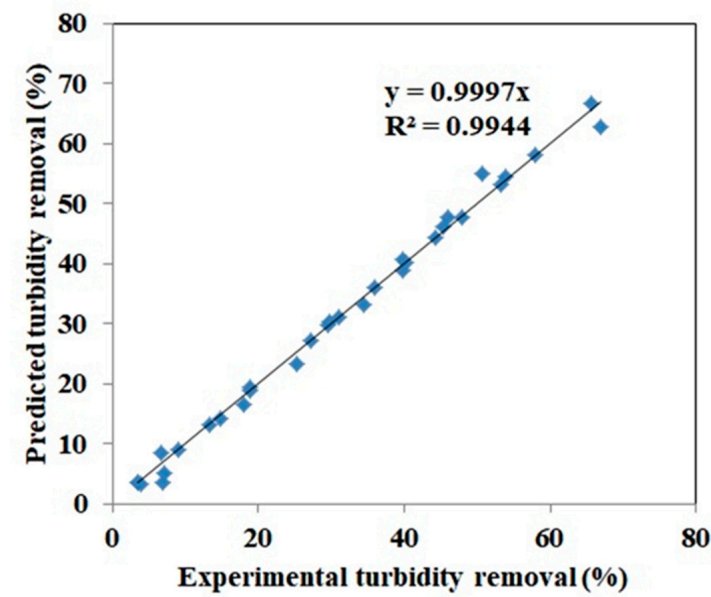

Figure 9. Experimental and SVM results for SD turbidity removal. 


\subsubsection{Optimization Data}

The optimization procedure was performed to find the value of the inputs that lead to the maximum value of turbidity removal. Given that the dimensionality of the problem is small (only 3 inputs), an exhaustive grid search was performed with the learned models. For more complex cases, an evolutionary algorithm could have been applied, for example, but in this case, it is not necessary because the problem space can be directly explored.

However, a special methodology was applied to compute the estimated value of the maximum turbidity removal. The best two kinds of models were used for this purpose: SVM and Random Forest. Using grid search, those models found the maximum value of the turbidity removal. This value was then scaled in proportion to the nearest value in the original dataset. For example, the best such values are the ones presented in Table 6.

Table 6. Best values in the original dataset.

\begin{tabular}{ccccc}
\hline $\begin{array}{c}\text { Instance } \\
\text { Id }\end{array}$ & $\begin{array}{c}\text { Disc } \\
\text { Rotational } \\
\text { Speed } \\
(\mathbf{r p m})\end{array}$ & $\begin{array}{c}\text { WW } \\
\text { Flowrate } \\
\mathbf{( L / h )}\end{array}$ & $\begin{array}{c}\text { Time } \\
(\mathbf{m i n})\end{array}$ & $\begin{array}{c}\text { Turbidity } \\
\mathbf{( \% )}\end{array}$ \\
\hline 2293 & 550 & 15 & 50 & 65.69 \\
5488 & 1200 & 15 & 60 & 66.86 \\
6923 & 1500 & 15 & 25 & 58.03 \\
\hline
\end{tabular}

While applying the grid search with the SVM model, the best turbidity removal value was the one obtained for the $(550,15,48)$ combination of inputs, i.e., $67.978 \%$ - called as solution a. However, this is only an estimation of the true optimal value, because the model is not perfect, thus we include a correction. The nearest best instance from Table 5 is (550, $15,50)$, whose output value is $66.726 \%$ in the SVM model-solution $b$, and $65.69 \%$ in the actual dataset-solution c. The correction is thus: $\mathrm{b}^{\prime}=\mathrm{b} \cdot \mathrm{a} / \mathrm{c}$.

In our particular case, $\mathrm{b}^{\prime}=65.69 \cdot 67.978 / 66.726=66.923 \%$. This is the value that can be seen on the last line of Table 7. It represents a better estimation of the optimal value of the turbidity removal for the $(550,15,48)$ instance.

Table 7. Best values obtained by SVM.

\begin{tabular}{ccccc}
\hline $\begin{array}{c}\text { Instance } \\
\text { Id }\end{array}$ & $\begin{array}{c}\text { Disc } \\
\text { Rotational } \\
\text { Speed (rpm) }\end{array}$ & $\begin{array}{c}\text { WW } \\
\text { Flowrate } \\
\text { (L/h) }\end{array}$ & $\begin{array}{c}\text { Time } \\
(\mathbf{m i n})\end{array}$ & $\begin{array}{c}\text { Turbidity } \\
\mathbf{( \% )}\end{array}$ \\
\hline 2293 & 550 & 15 & 50 & 66.726 \\
5488 & 1200 & 15 & 60 & 54.842 \\
6923 & 1500 & 15 & 25 & 58.002 \\
Selected & 550 & $\mathbf{1 5}$ & $\mathbf{4 8}$ & 67.978 \\
best2291 & & & & $\mathbf{6 6 . 9 2 3}$ \\
Scaled to2293 & & & & \\
\hline
\end{tabular}

In a similar way, the Random Forest model finds the estimated optimal value of turbidity as $67.825 \%$, for the $(650,15,48)$ combination of inputs, as shown in Table 8 . 
Table 8. Best values obtained by Random Forest.

\begin{tabular}{ccccc}
\hline $\begin{array}{c}\text { Instance } \\
\text { Id }\end{array}$ & $\begin{array}{c}\text { Disc } \\
\text { Rotational } \\
\text { Speed (rpm) }\end{array}$ & $\begin{array}{c}\text { WW Flowrate } \\
\text { (L/h) }\end{array}$ & $\begin{array}{c}\text { Time } \\
\text { (min) }\end{array}$ & $\begin{array}{c}\text { Turbidity } \\
\mathbf{( \% )}\end{array}$ \\
\hline 2293 & 550 & 15 & 50 & 56.787 \\
5488 & 1200 & 15 & 60 & 56.598 \\
6923 & 1500 & 15 & 25 & 45.524 \\
Selected & $\mathbf{6 5 0}$ & $\mathbf{1 5}$ & $\mathbf{4 8}$ & 58.633 \\
best2781 & & & & $\mathbf{6 7 . 8 2 5}$ \\
Scaled to2293 & & & & \\
\hline
\end{tabular}

\section{Discussion}

The SD technology was applied for a textile effluent treatment in association withcoagulation and advanced Fenton oxidation, the obtained results are encouraging for further continuing the research work.

For the real textile effluents, bentonite can be used as a coagulation adjuvant and/or discoloration agent. Thus, the coagulation of existing colloids is pursued to separate the existing suspended solids/colloids and/or newly formed precipitates of ferrous or ferric hydroxides (possible FO products), based on a combined mechanism of neutralizationadsorption/coprecipitation-adsorption/particles agglomeration (possible interparticle bridging) followed by a separation by settlement and/or filtration. The bentonite can act as discoloration agent based on a surface adsorption process of colored organics from aqueous system, possibly followed by gravitational settlement (sometimes, they remain in aqueous system as colloids). The colloids and/or suspended solids removal performance from industrial wastewaters can vary in the range of $20-40 \%$ by sedimentation, $30-60 \%$ by coagulation-sedimentation or $30-70 \%$ by coagulation-filtration, depending on effluent characteristics, $\mathrm{pH}$, coagulant/adjuvant concentration, flowrate, rotation speed, etc.

The performance of FO treatment for different aqueous systems can also vary in the range of $30-85 \%$ for color removal, depending on the initial characteristics of the real textile wastewater (not for simulated synthetic wastewater or dye solutions) such as the initial $\mathrm{pH}$ value (2.80-8.30) obtained when working with 0.018-0.35 $\mathrm{M} \mathrm{H}_{2} \mathrm{O}_{2}$ and $0.015-1.45 \mathrm{mM}$ $\mathrm{Fe}^{2+}$ and the reaction time (30 or $120 \mathrm{~min}$ ) [24]. The estimated performance of CWPO is of $20-90 \%$ and of photo-FO, of $10-90 \%$, however these require expensive catalysts or additional powerful, efficient UV lamps and thus, additional energy costs. Furthermore, in the scientific literature different mechanisms and numerous comparisons performed between different AOPs applied on different dye solutions or simulated synthetic textile wastewaters were reported, but only a few were applied on real industrial effluents. Thus, the classic Fenton reaction occurs only in the presence of ferrous ions $\left(\mathrm{Fe}^{2+}\right)$ which serve as electron donor for $\mathrm{H}_{2} \mathrm{O}_{2}$ but, additionally, diverse reaction paths which include both radicalic (HO- radicals) and non-radicalic mechanisms, implicating a few reactions of metallic species in the absence or presence of organic substrate, were proposed (of major importance for the biological and environmental systems). The non-radicalic mechanism of $\mathrm{FO}$ reaction suggests the reversible formation of intermediates, i.e., $\left[\mathrm{Fe}^{2+} \cdot \mathrm{H}_{2} \mathrm{O}_{2}\right]$ as principal intermediate, and $\left[\mathrm{FeO}^{2+}\right]$ as secondary key intermediate which can react with $\mathrm{Fe}^{2+}$ to produce $\mathrm{Fe}^{3+}$, or with $\mathrm{H}_{2} \mathrm{O}_{2}$ to form $\mathrm{O}_{2}$ [38]. The secondary intermediate can react also with $\mathrm{Fe}^{3+}$ to form binuclear species $\left([\mathrm{FeOFe}]^{5+}\right.$ ) that can react with $\mathrm{H}_{2} \mathrm{O}_{2}$ and eliberate $\mathrm{O}_{2}$, or decompose to $\mathrm{FeO}^{2+}$ and $\mathrm{Fe}^{3+}$. In this context, for the $\mathrm{FO}$ process a combined radicalic-non-radicalic mechanism is accepted. This will evolve particularly based on the treated industrial effluent characteristics, especially $\mathrm{pH}$, organic load and type, suspended solids content, etc. Therefore, the FO process is very suitable for advanced oxidation of textile effluents which inhibit biological treatment and are poisonous.The largest turbidity removal values obtained within the explored disc rotating speed and WW flowrate values, ranged from $3.90 \%$ up to $65.69 \%$ (both for $15 \mathrm{~L} / \mathrm{h}$, at $400 \mathrm{rpm}$ after $30 \mathrm{~min}$ and respectively, $550 \mathrm{rpm}$ after $50 \mathrm{~min}$ ) and for the discoloration, from $4.12 \%$ up to $43.30 \%$ (both for $10 \mathrm{~L} / \mathrm{h}$, 
at $100 \mathrm{rpm}$ after $18 \mathrm{~min}$ and respectively, $300 \mathrm{rpm}$ after $63 \mathrm{~min}$ ). Furthermore, some of the maximum values belong to increasing trends which indicates that even higher values could be obtained, if longer SD working time periods were used. Thus, the SD technology applied within the laboratory setup can be considered effective in textile effluent treatment, considering that no other physical, chemical or biological treatment process is applied.

The turbidity removal at different WW flowrates and disc rotational speeds larger than 500 rpm can be explained as follows: experimental observations indicated that on the liquid film surface fine ripples formed and persisted at rotational speeds above the mentioned value. These convective structures are associated with a more intense micromixing, fact supported by our higher removal values at higher disc rotational speeds. On the other hand, a liquid flowrate increase induces shorter residence times, meaning a diminished micromixing benefit despite the rotational speed increase. Also, the liquid flowrate has a lower impact on the mixing intensity than the disc rotational speed which is directly responsible for the generated shear stress.

The bentonite added to the textile effluent passed through the experimental SD setup had increased adsorption capability for colored organic and inorganic molecular and ionic species given the intensive micromixing. Thus, the discoloration was expected to increase and was detected in the experimental SD setup, for certain working conditions. Also, bentonite is known to help promote coagulation (as coagulation adjuvant). The process is typically initiated in the active working stage of the SD setup and continues in the passive non-working stage (the SD setup is not operated) when settling of the obtained solid agglomerates at the bottom of the collecting tank takes place. However, it is known that by varying the stirring speed, intensity, and time, in the first stage of coagulation, the turbidity removal is increased [37]. Thus, the high micromixing attained in the SD experimental setup had also a significant influence on improving the turbidity values (decrease of the colloidal particles content), at specific effluent flowrates and disc rotating speeds, within relatively short time periods. Additionally, if this WW treatment in the SD setup is discontinuous, after $24 \mathrm{~h}$ of rest in the final collecting tank, the removal of suspended solids and turbidity increases with more than 15-30\%, while for color, with 10-15\%. After applying an advanced oxidation step (FO) the laboratory SDR setup efficiency is improved, and the influence of $\mathrm{pH}$, hydrogen peroxide concentration and ferrous ions concentration were investigated and discussed. The highest color (62.84\%) and suspended solids (69.46\%) removals were obtained at $\mathrm{pH}=2.5$, with a hydrogen peroxide concentration of $14.91 \mathrm{mM}$ and an iron (II) concentration of $0.10 \mathrm{mM}$, after $25 \mathrm{~min}$ of SDR setup functioning.

Therefore, the global efficiency of textile WW treatment in the SD setup proves to be very efficient (higher than $70 \%$ ) for solids removal and stays in the lower range for discoloration (only 20-35\%). However, additional effluent treatment using Fenton's oxidation within the same laboratory SDR setup rendered improved color and suspended solids (implicitly turbidity) removals with maximum values at $\mathrm{pH}=2.5$, a hydrogen peroxide concentration of $14.91 \mathrm{mM}$ and a ferrous ions concentration of $0.10 \mathrm{mM}$.

Consequently, one can use this technology, either individually or associated with an advanced Fenton oxidation step, to minimize the turbidity load and, to some extent, the color, within relative short periods of time.

The modeling results showed that the best model for both regression models (turbidity removal and discoloration correlated with the working conditions) was the Support Vector Machine with a PUK kernel and an average value for the cost parameter. Random Forest also provided good results. With these models one can make predictions for various input data sets (not included in the experiment), thus saving time and materials.

This research underlines the possibility of further improvements by additional physicochemical or biological processes applied for complete $(100 \%)$ removals of color and suspended solids or turbidity. 


\section{Conclusions}

WW treatment improvement was achieved applying an advanced Fenton oxidation step simultaneously developed with SDR technology. Therefore, the influence of WW flowrate and disc rotational speed on the treatment process efficiency in terms of turbidity and color removal was studied (initially and in combination with the advanced oxidative treatment). Thus, for the investigated disc rotational speed and flowrate values, the highest turbidity removal values ranged from $3.90 \%$ up to $65.69 \%$ (both for $15 \mathrm{~L} / \mathrm{h}$, at $400 \mathrm{rpm}$ after $30 \mathrm{~min}$ and respectively, $550 \mathrm{rpm}$ after $50 \mathrm{~min}$ ) and for the discoloration, from $4.12 \%$ up to $43.30 \%$ (both for $10 \mathrm{~L} / \mathrm{h}$, at $100 \mathrm{rpm}$ after $18 \mathrm{~min}$ and respectively, $300 \mathrm{rpm}$ after $63 \mathrm{~min}$ ) which indicates a satisfactory efficiency of the SD technology with possible removal increase if longer SD operating time would be used. After the advanced Fenton oxidation step, the textile effluent treatment efficiency in the SDR setup was improved, the highest color $(62.84 \%)$ and suspended solids, implicitly turbidity (69.46\%) removals being performed at $\mathrm{pH}=2.5$, with a hydrogen peroxide concentration of $14.91 \mathrm{mM}$ and a ferrous ions concentration of $0.10 \mathrm{mM}$, after $25 \mathrm{~min}$ of SDR setup working. The textile effluent treatment modeling was achieved by using the support vector machine (SVM), M5Rules, random forest and linear regression, the latter only as a baseline for comparison. The best model in terms of regression correlation $(r)$ was Support Vector Machine $(66.923 \%$ turbidity removal) with a PUK kernel and an average value for the cost parameter, but also Random forest $(67.825 \%$ turbidity removal) at a rotation speed of $550 \mathrm{rpm}$, flowrate of $15 \mathrm{~L} / \mathrm{h}$ and working time of $48 \mathrm{~min}$. All the experimental results indicated beneficial improvement of the textile effluent treatment efficiency by combined FO and SDR technology and are encouraging for further research developments using this technique.

Supplementary Materials: The following are available online at https: / www.mdpi.com/article / 10.3390/pr9112003/s1, Figure S1: Turbidity removal dependence on WW flowrate at different disc rotational speeds: (a) $250 \mathrm{rpm}$, (b) $400 \mathrm{rpm}$, (c) $1500 \mathrm{rpm}$, Figure S2: Disc rotating speed effect on color removal, at different effluent flowrates: (a) $10 \mathrm{~L} / \mathrm{h}$, (b) $30 \mathrm{~L} / \mathrm{h}$, Table S1: Additional maximum values of turbidity removals at investigated SD operating parameter values, and Table S2: Maximum values of color removals at investigated SD operating parameter values.

Author Contributions: Conceptualization, C.Z., E.T.I.-T. and S.C.; methodology, C.Z.; software, F.L.; validation, C.Z., S.C. and E.T.I.-T.; formal analysis, E.T.I.-T. and F.L.; investigation, C.Z. and E.T.I.-T.; data curation, E.T.I.-T. and F.L.; writing-original draft preparation, E.T.I.-T., C.Z., S.C. and F.L.; writing-review and editing, C.Z., S.C. and E.T.I.-T.; supervision, E.T.I.-T. and C.Z.; project administration, E.T.I.-T.; funding acquisition, E.T.I.-T. All authors have read and agreed to the published version of the manuscript.

Funding: This research was funded by a publication grant of the TUIASI, project number GI/P33/2021.

Institutional Review Board Statement: Not applicable.

Informed Consent Statement: Not applicable.

Data Availability Statement: The supporting data are available upon request.

Conflicts of Interest: The authors declare no conflict of interest.

\section{References}

1. Boodhoo, K.V.K.; Jachuck, R.J. Process intensification: Spinning disc reactor for condensation polymerization. Green Chem. 2002, 2, 235-244. [CrossRef]

2. Raveendran, P.; Fu, J.; Wallen, S.L. Completely 'green' synthesis and stabilization of metal nanoparticles. J. Am. Chem. Soc. 2003, 125, 940-953. [CrossRef] [PubMed]

3. Wiesmann, U.; Choi, I.S.; Dombrowski, E.M. Fundamentals of Biological Wastewater Treatment; Wiley-VCH VerlagGmbH\&Co. KgaA: Weinheim, Germany, 2007.

4. Iacob-Tudose, E.T. Spinning Disc Reactor Technology for Environmental Chemical Processing: Design and Environmental Applications. Current Topics, Concepts and Research Priorities in Environmental Chemistry (III); Zaharia, C., Ed.; Alexandru Ioan Cuza" University Publishing House: Iasi, Romania, 2014; pp. 63-80. 
5. Qiu, Z.; Petera, J.; Weatherle, L.R. Biodiesel synthesis in an intensified spinning disk reactor. Chem. Eng. J. 2012, 210, 597-609. [CrossRef]

6. Ochando-Pulido, J.M.; Stoller, M.; Palma, L.; Martinez-Ferez, A.; Vilardi, G. Spinning disk reactor technology in photocatalysis: Nanostructured catalysts intensified production and applications. In Nanophotocatalysis and Environmental Applications. Materials and Technology; Springer: Berlin/Heidelberg, Germany, 2019; pp. 303-333. [CrossRef]

7. Chang, C.Y.; Wu, N.L. Process analysis on photocatalyzed dye decomposition for water treatment with TiO2-coated rotating disk reactor. Ind. Eng. Chem. Res. 2010, 49, 12173-12179. [CrossRef]

8. Dyonisos, D.D.; Balasubramanian, G.; Suidan, M.T.; Khodadoust, A.P.; Baudin, I.; Laine, J.M. Rotating disk photocatalytic reactor: Development, characterization and evaluation for the destruction of organic pollutants in water. Water Res. 2000, 349, 22-23. [CrossRef]

9. Zhang, A.Y.; Zhou, M.H.; Han, L.; Zhou, Q.X. The combination of rotating disk photocatalytic reactor and $\mathrm{TiO}_{2}$ nanotube arrays for environmental pollutants removal. J. Haz. Mat. 2011, 186, 1374-1383. [CrossRef]

10. Anirudhan, T.S.; Ramachandran, M. Adsorptive removal of basic dyes from aqueous solutions by surfactant modified bentonite clay (organoclay: Kinetic and competitive adsorption isotherm. Proc. Saf. Environ. Res. 2015, 95, 215-225. [CrossRef]

11. Aziz, A.; Moghaddam, M.R.A.; Maknoon, K.; Kowsari, E. Innovative combined technique for high concentration of azo dye AR18 wastewater treatment using modified SBR and enhanced Fenton process as post treatment. Proc. Saf. Environ. Res. 2015, 95, 255-264. [CrossRef]

12. Bilińska, L.; Gmurek, M.; Ledakowicz, S. Textile wastewater treatment by AOPs for brine reuse. Proc. Saf. Environ. Res. 2017, 109, 420-428. [CrossRef]

13. Ahn, D.H.; Chang, W.S.; Yoon, T.I. Dyestuff wastewater treatment using chemical oxidation, physical adsorption and fixed bed biofilm process. Proc. Biochem. 1999, 34, 111-114. [CrossRef]

14. Zaharia, C.; Suteu, D. Textile organic dyes-Characteristics, polluting effects, and separation/elimination procedures from industrial effluents. A critical overview. In Organic Pollutants-Ten Years After the Stockholm Convention-Environmental and Analytical Update; Puzyn, T., Mostrag-Szlichtyng, A., Eds.; Intech Publisher: Rijeka, Croatia, 2012; pp. 55-86.

15. IacobTudose, E.T.; Zaharia, C. Textile Wastewater Treatment on a Spinning Disc Reactor: Characteristics, Performance and Empirical Modeling. Appl. Sci. 2020, 10, 8687. [CrossRef]

16. Neyens, E.; Baeyens, J. A review of classic Fenton's peroxidation as an advanced oxidation technique. J. Haz. Mat. B 2003, 98, 33-50. [CrossRef]

17. Walling, C. Fenton's reagent revisited. Acc. Chem. Res. 1975, 8, 125-131. [CrossRef]

18. Hao, O.J.; Kim, H.; Chiang, P.C. Decolourization of wastewater. Crit. Rev. Environ. Sci. Technol. 2000, 30, 449-505. [CrossRef]

19. Ince, N.H.; Tezcanl, G. Treatability of textile dye bath effluents by advanced oxidation: Preparation for reuse. Water Sci. Technol. 1999, 40, 183-190. [CrossRef]

20. Joseph, J.M.; Varghese, R.; Aravindakumar, C.T. Photoproduction of hydroxyl radicals from Fe(III) hydroxy complex: A quantitative assessment. J. Photochem. Photobiol. A Chem. 2001, 146, 67-73. [CrossRef]

21. Lin, S.H.; Lo, C.C. Fenton process for treatment of desizing wastewater. Water Res. 1997, 31, 2050-2056. [CrossRef]

22. Kulik, N.; Panova, E.; Trapido, M. The Fenton chemistry and its combination with coagulation for treatment of dye solutions. Sep. Sci. Technol. 2007, 42, 1521-1534. [CrossRef]

23. Meriç, S.; Kaptan, D.; Olmez, T. Color and COD removal from wastewater containing Reactive Black 5 using Fenton's oxidation process. Chemosphere 2004, 54, 435-441. [CrossRef]

24. Zaharia, C.; Suteu, D.; Muresan, A.; Muresan, R.; Popescu, A. Textile wastewater treatment by homogenous oxidation with hydrogen peroxide. Environ. Eng. Manag. J. 2009, 8, 1359-1369. [CrossRef]

25. Zaharia, C.; Suteu, D.; Muresan, A. Options and solutions for textile effluent decolourization using some specific physico-chemical treatment steps. Environ. Eng. Manag. J. 2012, 11, 493-509. [CrossRef]

26. ***Standards Catalogue; AGIR (Ed.) Romanian Institute of Standards Publishing House: Bucuresti, Romania, 2015.

27. Drucker, H.; Burges, C.C.; Kaufman, L.; Smola, A.J.; Vapnik, V.N. Support Vector Regression Machines. In Advances in Neural Information Processing Systems 9, NIPS 1996; MIT Press: Cambridge, MA, USA, 1997; pp. 155-161.

28. Holmes, G.; Hall, M.; Frank, E. Generating Rule Sets from Model Trees. Twelfth Australian Joint Conference on Artificial Intelligence, AI '99; Springer: Berlin/Heidelberg, Germany, 1999; Volume 1747, pp. 1-12.

29. Breiman, L. Random Forests. Mach. Learn. 2001, 45, 5-32. [CrossRef]

30. Frank, E.; Hall, M.A.; Witten, I.H. The WEKA Workbench. Online Appendix for "Data Mining: Practical Machine Learning Tools and Techniques", 4th ed.; Morgan Kaufmann: Cambridge, MA, USA, 2016.

31. Zaharia, C.; Fedorcea, V.; Beda, A.; Amarandei, V.; Muresan, A. Removal of Remazol Rosso RB dye from aqueous effluents by homogenenous Fenton oxidation processes. Chem. J. Mold. 2014, 9, 74-79. [CrossRef]

32. Iacob-Tudose, E.T.; Zaharia, C. Spinning Disc Technology-Residence Time Distribution and Efficiency in Textile Wastewater Treatment Application. IOP Conf. Ser. Mat. Sc. Eng. 2018, 374, 12037. [CrossRef]

33. Gregory, J. Industrial Water Soluble Polymers; Royal Society of Chemistry: London, UK, 1996.

34. Zaharia, C. Decentralized wastewater treatment systems: Efficiency and its estimated impact against onsite natural water pollution status. A Romanian case study. Proc. Saf. Environ. Res. 2017, 108, 74-88. [CrossRef] 
35. Zaharia, C. Application of waste materials as 'low cost' sorbents for industrial effluent treatment: A comparative overview. Int. J. Mat. Prod. Tech. 2015, 50, 196-220. [CrossRef]

36. Uestuen, B.; Melssen, W.J.; Buydens, L.M.C. Facilitating the application of Support Vector Regression by using a universal Pearson VII function based kernel. Chem. Intell. Lab. Syst. 2006, 81, 29-40. [CrossRef]

37. Sanchez, M.; Beltran-Heredia, J.; Peres, J.A. Improvement of the flocculation process in water treatment by using moringa oleifera seeds extract. Braz. J. Chem. Eng. 2012, 29, 495-501. [CrossRef]

38. Musteret, C.; Fighir, D.; Gavrilescu, D.; Zaharia, C.; Teodosiu, C. Water and Wastewater Treatment_Practice Applications; Politehnium, Ed.; “Gheorghe Asachi” Technical University of Iasi Publishing House: Iasi, Romania, 2014. (In Romanian) 